\title{
WestVirginiaUniversity
}

THE RESEARCH REPOSITORY @ WVU

Graduate Theses, Dissertations, and Problem Reports

2012

\section{Evaluation of Treatment Integrity Errors on Mand Acquisition}

Sacha T. Pence

West Virginia University

Follow this and additional works at: https://researchrepository.wvu.edu/etd

\section{Recommended Citation}

Pence, Sacha T., "Evaluation of Treatment Integrity Errors on Mand Acquisition" (2012). Graduate Theses, Dissertations, and Problem Reports. 3548.

https://researchrepository.wvu.edu/etd/3548

This Dissertation is protected by copyright and/or related rights. It has been brought to you by the The Research Repository @ WVU with permission from the rights-holder(s). You are free to use this Dissertation in any way that is permitted by the copyright and related rights legislation that applies to your use. For other uses you must obtain permission from the rights-holder(s) directly, unless additional rights are indicated by a Creative Commons license in the record and/ or on the work itself. This Dissertation has been accepted for inclusion in WVU Graduate Theses, Dissertations, and Problem Reports collection by an authorized administrator of The Research Repository @ WVU.

For more information, please contact researchrepository@mail.wvu.edu. 
Evaluation of Treatment Integrity Errors on Mand Acquisition

\author{
Sacha T. Pence
}

\author{
Dissertation submitted to the \\ Eberly College of Arts and Sciences \\ at West Virginia University \\ in partial fulfillment of the requirements \\ for the degree of \\ Doctorate of Philosophy \\ in \\ Psychology
}

Claire St. Peter, Ph.D., Chair

Michael Perone, Ph.D.

Elizabeth Kyonka, Ph.D.

Christina Duncan, Ph.D.

Michael Mayton, Ph.D.

Department of Psychology

Morgantown, West Virginia

2012

Keywords: commission errors; mand training; omission errors; skill acquisition; treatment integrity 


\section{ABSTRACT \\ Evaluation of Treatment Integrity Errors on Mand Acquisition}

\section{Sacha T. Pence}

Manding (requesting) is a vital component of successful language development and allows children to access reinforcers in their environment. When training mands, caregivers may not implement the training program as designed ("treatment integrity failures"). The purpose of the current study was to evaluate the effects of incorrect-item delivery (Experiment 1) and responseindependent item delivery (Experiment 2 ) across four levels of treatment integrity $(0 \%, 40 \%$, $70 \%$, and $100 \%$ ) on mand acquisition. A total of six children (three in each experiment), who communicated vocally using full sentences and engaged in some independent manding participated in the study. During Experiment 1, two of the three participants acquired the mand fastest during $100 \%$ integrity. Delivery of the incorrect item was detrimental to mand acquisition, but the effects were idiosyncratic across the two participants. The third participant did not acquire any mands. During Experiment 2, all three participants acquired the mand fastest during the $100 \%$ integrity condition. All participants acquired the mand trained with $70 \%$ integrity. None of the participants acquired the mands trained with $40 \%$ and $0 \%$ integrity, suggesting that delivery of the item independent of responding was detrimental to acquisition. For mand training to be most effective, caregivers must implement mand training with high levels of integrity. 


\section{Acknowledgements}

I would like to thank Claire St. Peter, Mike Perone, Liz Kyonka, Christina Duncan, and Michael Mayton for serving on my dissertation committee and for their valuable input in preparing this manuscript. I would especially like to thank Claire St. Peter for serving as the chair of my committee and for her contributions to this manuscript. I would also like to thank Aimee Giles, Lindsay Jackson, and Maddie Colley for their help as therapists and with data collection. 
Table of Contents

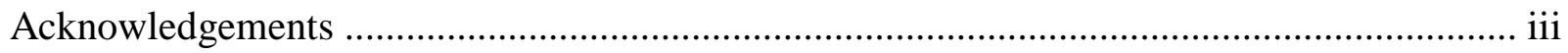

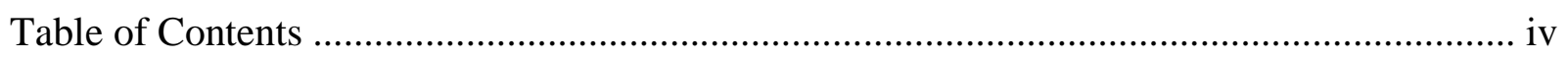

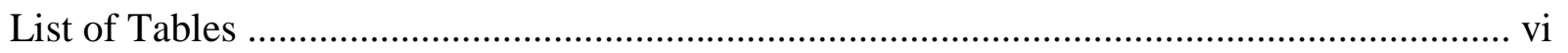

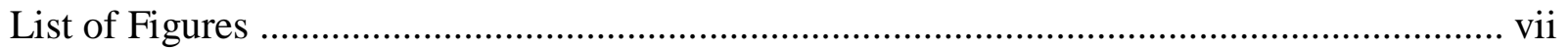

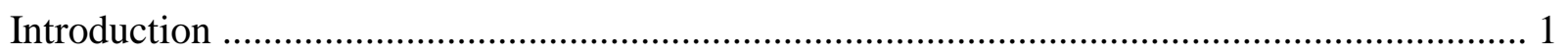

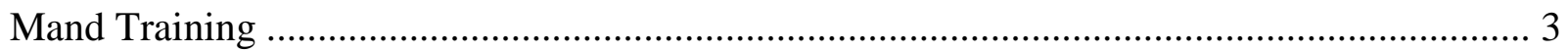

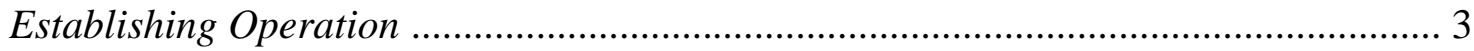

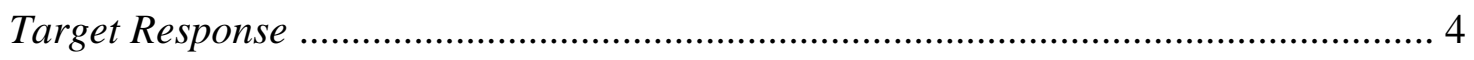

Reinforcement ................................................................................................ 7

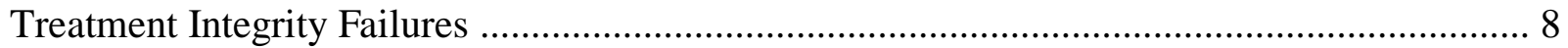

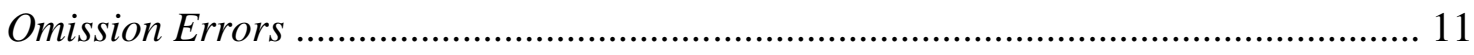

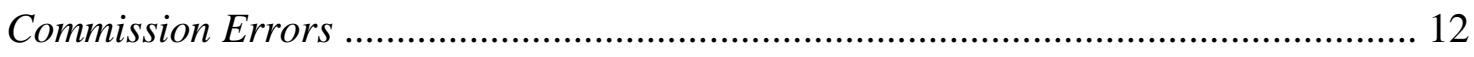

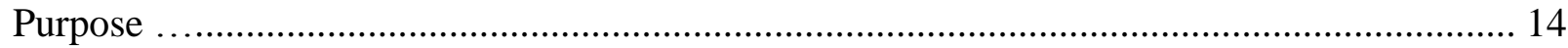

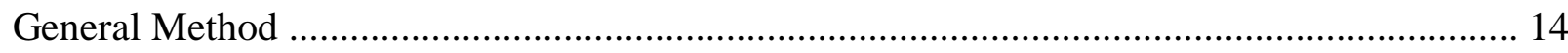

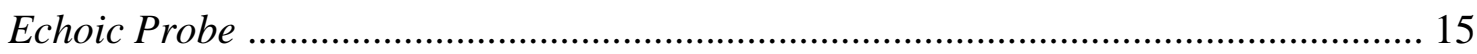

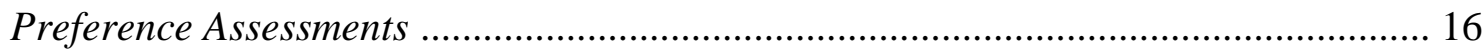

Experiment 1: Incorrect Item Delivery ….............................................................. 18

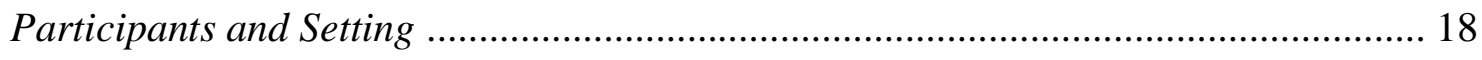

Data Collection and Interobserver Agreement .......................................................18

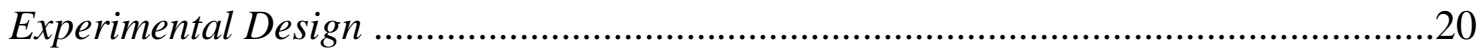

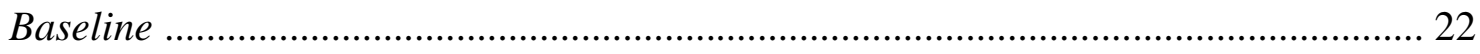

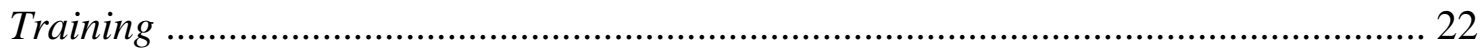

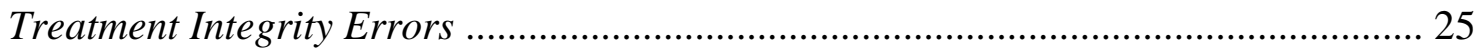

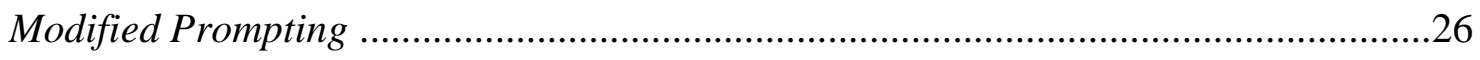

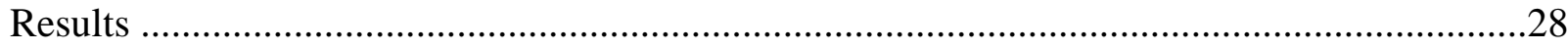

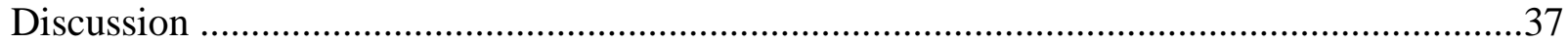

Experiment 2: Response-Independent Item Delivery …............................................40

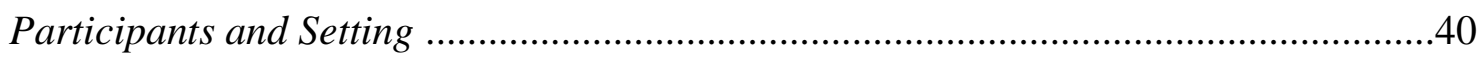

Data Collection and Interobserver Agreement .....................................................41

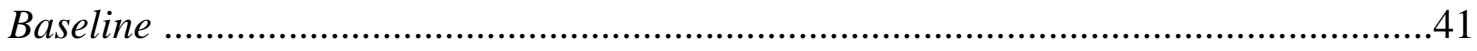




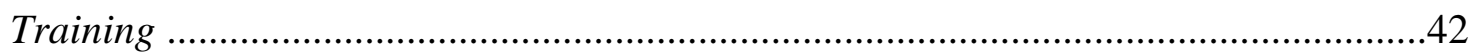

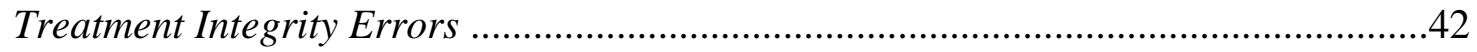

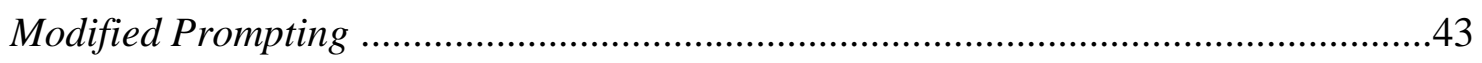

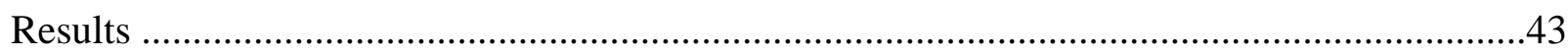

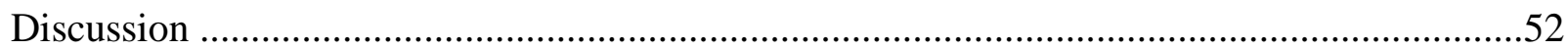

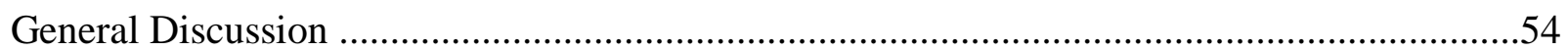

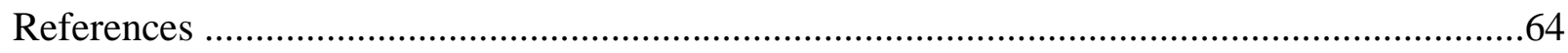

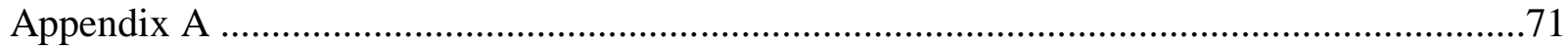

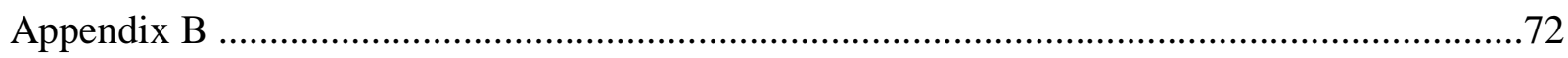

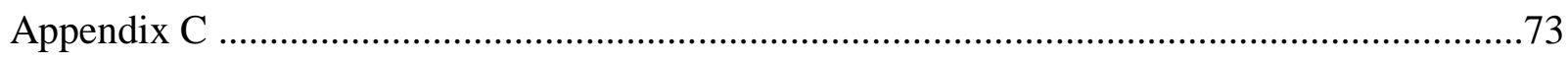

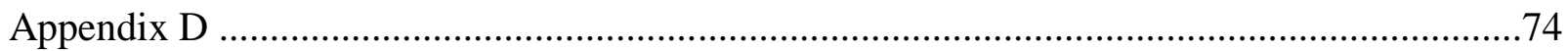




\section{List of Tables}

Table 1: Summary of Interobserver Agreement ......................................................... 21

Table 2: Non-target Items and Assigned Nonsense Names for Isaac .................................... 27

Table 3: Assigned Nonsense Names for Participants and Conditions .................................... 32

Table 4: Summary of Independent Target Mands and Session Termination for Experiment 1.. 36

Table 5: Summary of Independent Target Mands and Session Termination for Experiment 2.. 51 


\section{List of Figures}

Figure 1: Percentage of opportunities on which a particular toy was selected during MSWO preference assessments across the four sets of toys for Miles. .............................29

Figure 2: Percentage of opportunities on which a particular toy was selected during MSWO preference assessments across the four sets of toys for Paige. ........................... 30

Figure 3: Percentage of opportunities on which a particular toy was selected during MSWO preference assessments across the four sets of toys for Isaac. ............................ 31

Figure 4: Percentage of opportunities on which a particular toy was selected during MSWO preference assessment with the four highest preferred items from each set of toys for Miles (top panel), Paige (middle panel), and Isaac (bottom panel).

Figure 5: Percentage of correct independent mands with incorrect item delivery during 0\%, $40 \%, 70 \%$, and $100 \%$ integrity sessions across baseline and training for Miles (top panel), Paige (middle panel), and Isaac (bottom panel). .35

Figure 6: Percentage of opportunities on which a particular toy was selected during MSWO preference assessments across the four sets of toys for Keith.

Figure 7: Percentage of opportunities on which a particular toy was selected during MSWO preference assessments across the four sets of toys for Mitch. ...........................46

Figure 8: Percentage of opportunities on which a particular toy was selected during MSWO preference assessments across the four sets of toys for Logan.

Figure 9: Percentage of opportunities on which a particular toy was selected during MSWO preference assessment with the four highest preferred items from each set of toys for Keith (top panel), Mitch (middle panel), and Logan (bottom panel). .48

Figure 10: Percentage of correct independent mands with incorrect item delivery during 0\%, $40 \%, 70 \%$, and $100 \%$ integrity sessions across baseline and training for Keith (top panel), Mitch (middle panel), and Logan (bottom panel). .50 


\section{Evaluation of Treatment Integrity Errors on Mand Acquisition}

Requesting is a vital component for successful language and behavioral development during childhood. Requesting allows children to communicate for items, actions, attention, removal of aversive stimuli, and information (all of which may function as rewards or reinforcers). Children with delayed, weak, or no requesting skills may have difficulty accessing reinforcers in their environment. As a consequence, children may develop socially inappropriate behavior (e.g., aggression, self-injury) to acquire reinforcers from other people.

Skinner (1957) labeled requests as mands. Mands are a verbal operant that are under the control of an establishing operation and maintained by the reinforcer specified in the request. Establishing operations are environmental variables that increase the effectiveness of a reinforcing stimulus and result in an increase in behavior that has been previously reinforced by that stimulus (Michael, 1982). For example, food deprivation is an establishing operation that increases the effectiveness of food as a reinforcer and increases the likelihood of behavior that has been previously reinforced by gaining access to food. In the case of a mand, if a child has not eaten in five hours, the child may state, "Can I have a sandwich please?" In this example, the response is under the control of the establishing operation of food deprivation (the child has not eaten in five hours). The response "Can I have a sandwich please?" is more likely to occur because this response has previously resulted in the delivery of food when the child was hungry.

Mands are reinforced by the delivery of the stimulus specified in the request. For example, the mand "Can I have a sandwich please," would be reinforced by the delivery of a sandwich. The listener (e.g., parent, teacher) plays an important role in shaping manding. Once the child emits a mand, the listener facilitates the delivery of the requested item. With our 
example, if the child asks for a sandwich, the mother would make a sandwich and give it to the child, reinforcing the mand, "Can I have a sandwich please?"

When children do not develop appropriate manding, problem behavior may serve the function of the missing mand in the child's repertoire. Problem behavior often serves one or more social functions and can be maintained by the delivery of attention, removal of aversive stimuli (e.g., demands), and access to tangible items (Day, Rea, Schussler, Larsen, \& Johnson, 1988; Iwata, Dorsey, Slifer, Bauman, \& Richman, 1982/1994). The establishing operation in place (restriction of attention, aversive task, restriction of favorite toy) increases the value of these reinforcers. For children who have appropriate mands in their repertoires, a request is more likely to occur given a specific establishing operation. For example, during restricted attention, a child may ask, "Can we talk please?" resulting in the delivery of adult attention. During an aversive task, the child may ask, "Can I have a break please?" Following such a request, the task would be removed or postponed. During the restriction of a favorite toy, the child may ask, "Can I have my bear?" resulting in the delivery of the bear. Children without appropriate mands in their repertoires may engage in problem behavior under the control of these same establishing operations to access adult attention, task removal, or the delivery of their favorite toy. For example, a child may run away from an adult because doing so leads to the adult chasing or reprimanding the child. During an aversive task, the child may hit the adult, resulting in the adult removing the task. During the restriction of a favorite toy, the child may tantrum, scream, and flop to the floor, resulting in the re-presentation of the toy. 


\section{Mand Training}

Mand training involves three general components. First, the therapist needs to create an establishing operation or use a naturally occurring establishing operation. Second, the child must engage in the target response (mand). Finally, the therapist must reinforce the target mand.

\section{Establishing Operation}

Establishing operations occur naturally throughout the day and can be used as incidental opportunities to teach mands. However, therapists can increase the number of learning opportunities by manipulating the environment to create potential establishing operations. Within teaching arrangements, an establishing operation may be contrived by restricting an item or activity (Bourret, Vollmer, \& Rapp, 2004; Simic \& Bucher, 1980) or restricting attention (Brown et al., 2000; Carr \& Durand, 1985). For example, Carr and Durand trained children to ask, “Am I doing good work?" as a mand for attention under conditions in which attention was withheld.

Establishing operations can also be arranged by presenting an aversive stimulus (e.g., demands; Winborn, Wacker, Richman, Asmus, \& Geier, 2002; Yamamoto \& Mochizuki, 1988), withholding parts of items (Jennett, Harris, \& Delmolino, 2008), and withholding information to locate preferred stimuli (Koegel, Koegel, Green-Hopkins, \& Barnes, 2010; Shillingsburg, Valentino, Bowen, Bradley, \& Zavatkay, 2011). By creating demanding (aversive) conditions, therapists can teach children to mand for assistance or a break from the task. By withholding information, children can be taught to mand using where, when, who, and which questions. For example, Shillingsburg and colleagues (2011) taught children to ask for information (who) by restricting access to a favorite item and stating, "someone has [favorite item]." 
If the parent, teacher, or caregiver does not create an establishing operation, children may not develop functional mands. In these cases, children may not ask for things that should be under the control of establishing operations. For example, if a parent has attempted to teach a child to ask for a coat, but conducts sessions in a warm environment, then the establishing operation (being cold) is not in place to teach the child to ask for a coat when cold. In similar cases, children may not ask for items that are missing or required to complete a task. For example, a child may not ask for a pencil during class. However, if the teacher always provides the child with a pencil during writing activities, then the establishing operation is never in place to teach the mand. Long-term outcomes of these individuals failing to develop mands include an increased probability of being labeled as noncompliant or having behavioral disorders when actually they have skill deficits. For example, a High School student who sits at his desk and does not complete his work is likely to be labeled as noncompliant by his teacher. However, the issue is that the student does not have the skills necessary to ask for missing items (pencil, paper, etc.) to complete his work.

\section{Target Response}

Mand training occurs similarly across all response topographies. The three most commonly used mand topographies are vocal (e.g., Bourret et al., 2004; Shillingsburg et al., 2011; Yamamoto \& Mochizuki, 1988), sign (e.g., Brown et al., 2000; Carr \& Kologinsky, 1983), and exchange-based systems (e.g., Gregory, DeLeon, \& Richman, 2009; Tincani, 2004). Vocal mands include the child emitting vocal statements, such as the word "cookie." Sign mands include nonvocal statements using sign language. For example, the child can sign "cookie." Exchange-based systems involve the child selecting a graphic symbol (a picture of a cookie) and handing the graphic symbol to the listener. 
Although the response topography selected for training varies depending on the repertoire of the participant and the verbal community, the most commonly selected topography is vocal mands. Vocal mands have an advantage over exchanged-based communication systems and signs because of the increased number of potential listeners that could reinforce mands in the natural environment. Vocal manding can be established for access to edibles (Kodak \& Clements, 2009; Simic \& Bucher, 1980), objects (Bourret et al., 2004; Petursdottir, Carr, \& Michael, 2005; Yamamoto \& Mochizuki, 1988), actions (Bowman, Fisher, Thompson, \& Piazza, 1997; Carr \& Durand, 1985), information (Ingvarsson \& Hollobaugh, 2010), removal of aversive stimuli (Brown et al., 2000), and attention (Tiger \& Hanley, 2004). Manding established in experimental contexts has persisted with novel people and in the natural environment (Simic \& Bucher).

Across all potential mand topographies, mand training frequently includes a prompting procedure. Prompting to teach signs or exchange-based systems may include verbal directives (e.g., "If you want this, touch [graphic symbol name]), models (e.g., demonstration of the sign), and physical guidance (e.g., using hand-over-hand to have the child sign or exchange the picture; Tincani, 2004). When training vocal mands, prompting may include nonspecific statements (e.g., "What do you want?" or "What do you need?"), partial models (e.g., saying the first sound of the response), and full models of the target response (e.g., saying the entire response; Bourret et al., 2004).

The structure of the prompts typically occurs in one of two ways: least-to-most prompting or most-to-least prompting. Least-to-most prompting involves the therapist providing the opportunity for the child to respond independently and then gradually increasing the intrusiveness of the prompt as needed until a correct response occurs. Most-to-least prompting 
involves providing the most intrusive prompt initially and then systematically fading the prompts until the child is responding correctly and independently. Both least-to-most prompting (e.g., Kodak \& Clements, 2009; Winborn-Kemmerer, Ringdahl, Wacker, \& Kitsukawa, 2009) and most-to-least prompting (Carr \& Durand, 1985; Tincani, 2004) have been frequently reported in the literature and have been successfully used to teach manding.

Both least-to-most and most-to-least prompting procedures have advantages and disadvantages to consider when implementing mand-training procedures. Most-to-least prompting is typically associated with fewer errors during training, but requires more training sessions for mastery of a skill (Libby, Weiss, Bancroft, \& Ahearn, 2008). Children may acquire skills faster with least-to-most prompting, but make more errors during training (Libby et al., 2008). Therefore, the prompting procedures used during mand training often depend on the skills of the individual and judgments about whether errors during acquisition are likely to impede learning or increase problem behavior.

As training progresses, the therapist must ensure that the mand is under the control of the relevant establishing operation and is not dependent upon prompting. The most prevalent prompt-fading technique reported in the literature is the use of a time delay (e.g., Ingvarsson \& Hollobaugh, 2010; Jennett et al., 2008; Shirley, Iwata, Kahng, Mazaleski, \& Lerman, 1997; Tincani, 2004). A time delay involves the therapist allowing a set duration of time to elapse between the arrangement of the establishing operation and the delivery of a prompt. The time delay provides the child with the opportunity to emit the mand independently. Time delays can be used in combination with least-to-most and most-to-least prompting. For example, Kodak and Clements (2009) inserted a 5-s delay between least-to-most prompting levels (nonspecific prompt and echoic prompt). 
Eventually, prompting must be discontinued. If the child is not required to emit the target response independently by the end of training, the child may fail to emit the mand without some level of prompting. For example, if the therapist does not fade the use of a partial prompt, the child may only mand for an item following the initial sound of the response. In other situations, if the child is not required to engage in the target response to gain access to the target item, the child may not emit the response even when the relevant establishing operation is present. For example, if a teacher only requires the child to ask for a spoon once a week during lunch, then the child may not ask for a spoon even when one is required to eat his lunch. Instead the child may wait to see if the teacher will bring him a spoon. The use of prompting to occasion the target mand is an important component of training. Therapists must consider and design mandtraining procedures that involve frequent manding opportunities, a prompting procedure that is appropriate for the mand topography, and appropriate fading procedures.

\section{Reinforcement}

The therapist must reinforce the target mand by delivering the item, activity, action, information, etc. requested. The use of differential reinforcement involves the therapist delivering the reinforcing stimulus following the target mand and withholding the stimulus following incorrect responses. For example, Shillingsburg and colleagues (2011) provided children information about the location of a missing item only when the child asked, "Where is [name of missing item]?" The information about the location was withheld if the child did not engage in the correct mand.

Differential reinforcement can also be used to increase the likelihood of the participant engaging in an independent mand instead of a prompted mand. Bourret and colleagues (2004) trained mands during 1-min trials. If participants manded correctly at any point during the trial, 
the item was delivered. Participants had $10 \mathrm{~s}$ to respond independently before a nonspecific prompt was delivered. Participants had an additional $10 \mathrm{~s}$ to respond before an echoic prompt was delivered. If participants responded earlier in the trial, they received a greater duration of access to the item. Therefore, independent responses resulted in a greater duration of reinforcement than prompted responses. This use of differential reinforcement was successful in increasing independent manding for all participants.

Failure to reinforce the target response can result in deficits in the child's manding repertoire. For example, if a child asks for a "coat" and the teacher never provides access to a coat, then it is unlikely that the child will continue to ask for a coat even in situations in which he is cold. Alternatively, if a child asks for "milk" and the teacher provides him with juice, the child may learn that "milk" results in delivery of juice. The child may have a deficient mand in which he asks for "milk" when he wants juice and does not have a mand to ask for milk. This would be problematic when the child interacts with other listeners in his environment (e.g., unfamiliar adults, waitress in a restaurant). When the child asks for "milk" with other listeners, they may provide him with milk. However, the controlling establishing operation for the response "milk" is not the absence of milk, but instead the absence of juice. The child wants juice and has learned that saying "milk" results in juice. The delivery of milk in this situation may lead to increases in problem behavior (e.g., the child cries or throws the milk). These unfamiliar adults do not have access to the child's learning history to know that "milk" is actually a mand for juice.

\section{Treatment Integrity Failures}

Although previous research has established the conditions under which mands can be successfully trained, mand training may not occur as planned due to extraneous variables. 
Numerous types of errors may occur during mand training, including errors made during arrangement of establishing operations, prompting, response-reinforcer contingencies, errorcorrection procedures, and delivery of the item. Two errors that may occur in the natural environment are the delivery of an incorrect item and the delivery of the item independent of the occurrence of a mand.

The delivery of an incorrect item results in an inconsistency between the child's mand and the delivery of the requested item. Some children have speech delays or articulation problems, making it difficult for listeners (e.g., caregivers and teachers) to understand the vocal statement. When the listener fails to understand the mand, he or she may make a "best guess" about what was requested or deliver another known preferred item instead. Similarly, the listener may provide access to another item following a mand in situations where the requested item is currently unavailable (e.g., requesting a McDonald's hamburger in the middle of the school day). In these cases, the item delivered does not correspond to the child's mand. For example, the child may request "chips," but the listener provides the child with cookies instead. Although no study to date has examined this type of error during mand training, the delivery of incorrect items may result in a generalized mand where the child learns that one response (e.g., "chips") results in the delivery of many different items (e.g., chips, cookies, candy, cars, and crayons). As a consequence, the child may make one response as a mand for many items instead of developing discriminated responses for each item.

Another error that occurs in the natural environment is when the target items are made available to the child outside of training contexts and delivered to the child independent of manding. This may occur when teachers are training a child to mand for an item at school (e.g., videos), but the parents deliver that item (videos) to the child at home without requiring the child 
to mand. Teachers and caregivers may also deliver a preferred item following other appropriate behavior (e.g., following directives) even if that item is currently involved in mand training. Although no study to date has explicitly evaluated this type of error during mand training, the arrangement of these contingencies may impede the acquisition of the target mand because the reinforcer is delivered following other behavior or independent of child behavior.

Deviations from the mand-training procedures, including incorrect item delivery and response-independent delivery, are treatment integrity errors. Treatment integrity can be defined as the implementation of a protocol (e.g., intervention or academic program) in the manner in which it was designed (DiGennaro, Martens, \& Kleinmann, 2007; DiGennaro Reed, Reed, Catania, \& Maquire, 2011). Higher levels of treatment integrity during behavior-reduction interventions result in better outcomes (St. Peter Pipkin, Vollmer, \& Sloman, 2010; Vollmer, Roane, Ringdahl, \& Marcus, 1999). Similarly, lower levels of treatment integrity have detrimental effects on skill acquisition (DiGennaro Reed et al., 2011; Noell, Greshman, \& Gansle, 2002; Worsdell et al., 2005). In other words, the more consistently therapists implemented the protocol as designed, the more successful the treatment was in decreasing problem behavior or increasing a new appropriate behavior.

Previous investigations have examined treatment integrity errors on the acquisition of various skills, including math skills (Noell et al., 2002) and sight words (Worsdell et al., 2005). The results from skill-acquisition studies are directly applicable to the development of other skills, including manding. Although a variety of training procedures are used across different skill-acquisition programs, the skill-acquisition literature can inform training practices that are likely to result in greater rates of mand acquisition. 


\section{Omission Errors}

Several kinds of treatment integrity errors have been reported in the literature. One type of treatment integrity errors are omission errors. Omission errors occur when components of the protocol are not implemented (Noell et al., 2002). For example, mand training often includes a prompting procedure to evoke the target response. Failure to provide the prompt as prescribed would be an omission error. Similarly, failure to provide the item specified in the mand (e.g., a child asks for "milk" and the caregiver does not provide milk), is an example of an omission error.

Omission errors may be detrimental to the acquisition of new skills. Several studies have evaluated the effects of errors of omission during prompting procedures. For example, Noell and colleagues (2002) obtained higher levels of correct responding for 10 of 12 participants when prompting was implemented at $100 \%$ integrity compared to $67 \%$ integrity. Furthermore, implementation of prompting at 33\% integrity was detrimental to correct responses across all 12 participants. Wilder, Atwell, and Wine (2006) observed reduced levels of compliance as treatment integrity decreased $(100 \%, 50 \%$, and $0 \%)$. Grow and colleagues (2009) found that omission of physical guidance prompts resulted in slower acquisition for three of four participants. Taken together, these studies highlight the importance of structured prompting procedures on acquisition rates and how failure to implement procedures as outlined can alter the effectiveness of academic programming. A structured prompting procedure should be followed during mand training for acquisition to occur because omission of prompts (e.g., failure to provide prompts for the correct response) may be detrimental to the acquisition of a new mand.

Omission errors may occur during other components of instruction, such as errorcorrection procedures. Error-correction procedures commonly involve re-presenting a learning 
trial and having the child practice the correct response. During mand training, a therapist may use an error-correction procedure when a child makes an incorrect response instead of the target mand. For example, if a child said "chip," but refused the chip offered by the therapist and pointed to the cookie, the therapist may withdraw the chip, model the correct response ("cookie") and then deliver the cookie only after the child said "cookie."

Error-correction procedures should occur after every incorrect response. Worsdell and colleagues (2005) evaluated omission errors in which error-correction procedures either followed every incorrect response (100\% integrity) or a third of incorrect responses (33\% integrity). More skills were acquired when the error-correction procedure was implemented with $100 \%$ integrity. Therefore, when error-correction procedures are used during mand training, greater rates of acquisition are likely to occur when the error-correction procedure is consistently implemented after every incorrect mand.

\section{Commission Errors}

Commission errors are another type of treatment integrity error that can occur during mand training. Commission errors are the implementation of procedures that are not prescribed by the protocol (DiGennero Reed et al., 2011). For example, mand training typically involves restriction of the target item and then presentation of that item contingent on the target response (mand). The delivery of the target item independently of responding would be a commission error.

Few studies have investigated the effects of commission errors on skill acquisition. In one notable exception, DiGennaro Reed and colleagues (2011) taught children to identify nonsense shapes. During the training procedures, commission errors were introduced during all, half, or none of the training trials. Commission errors consisted of delivery of a token and social 
praise before the error-correction procedure was implemented. Correct responding occurred most frequently when procedures were implemented correctly (no commission errors).

Commission errors on 50\% (50\% integrity) and $100 \%$ ( $0 \%$ integrity) of trials had detrimental effects on correct performance. For two of three participants, levels of correct responding were similar in the 50\% and $0 \%$ integrity conditions, suggesting that commission errors on half of trials were as detrimental to acquisition as errors on all trials. This study informs procedures to teach mands, suggesting that delivering the item and then prompting the child to emit the correct response (e.g., the child says "chip," and the therapist first delivers the cookie and then prompts the child to say "cookie") may be detrimental to mand acquisition.

Response-independent reinforcement involves the delivery of a reinforcer independent of child's responding, and can be conceptualized as another type of commission error during mand training. A reliable finding across both nonhumans (Lattal \& Maxey, 1971; Lieving, Reilly, \& Lattal, 2006) and humans (Kahng, Iwata, Thompson, \& Hanley, 2000; Vollmer, Iwata, Zarcone, Smith, \& Mazaleski, 1993) is that response-independent reinforcer delivery results in decreased rates of responding compared to response-dependent reinforcer delivery. Response-dependent and response-independent contingences often operate simultaneously in the natural environment. For example, a child may mand for teacher attention by stating, "Ms. Miller, look what I did." The child's mand may be reinforced with teacher attention intermittently (e.g., after approximately every three mands the child makes). In addition, the teacher may come over to the student periodically and provide attention independently of responding. A blending of response-dependent and response-independent contingencies may result in decreased rates of manding. For example, Lattal (1974) compared conditions where reinforcers were delivered on different proportions of response-dependent to response-independent delivery. Response rates 
were highest during the $100 \%$ response-dependent reinforcement condition and decreased as a function of the percentage of response-independent reinforcer deliveries. Although this study did not examine manding, the results suggest that response-independent delivery of reinforcers during mand training could have significant implications for acquisition of the target response.

Few studies have evaluated the effects of response-independent reinforcer delivery during academic skills. In one notable exception, Luczynski and Hanley (2010) compared rates of responding on an academic task when reinforcers were delivered dependent on responding or independent of responding. Rates of responding decreased to low levels when reinforcers were delivered independent of responding, suggesting that reinforcers must be delivered contingent on responding for skills to maintain. During mand training, providing the reinforcing stimulus independent of responding may have detrimental effects on rates of mand acquisition.

\section{Purpose}

Although lower levels of treatment integrity impede the acquisition of academic-related skills, no research to date has examined the effects of treatment integrity errors during mand acquisition. The proposed study evaluated two types of treatment integrity errors on levels of independent target mands during mand acquisition. Experiment 1 examined the effects of incorrect item delivery. Experiment 2 examined the effects of response-independent delivery of the target item.

\section{General Method}

Participants with the necessary behavioral repertoires were screened to be enrolled in the study. Participants needed to communicate vocally using full sentences, emit some independent mands in their classrooms, be able to sit in a chair for at least $10 \mathrm{~min}$, follow one-step directives, imitate two-syllable nonsense words, have some history of receiving instruction in a small group 
or one-to-one, and engage with toys. Participants with the necessary behavioral repertories were referred by their teachers. Parents were asked to provide written consent as outlined by the West Virginia University IRB protocol.

Each participant was exposed to four conditions with varying levels of treatment integrity $(0 \%, 40 \%, 70 \%$, and $100 \%$ integrity) during the baseline and training phases of the experiment. The purpose of these conditions was to parametrically evaluate how treatment integrity errors affected rates of mand acquisition during training. Prior to starting the experiment, participants completed an echoic probe and a series of preference assessments. The echoic probe measured the participant's existing echoic repertoire of two-syllable words and was used to screen participants for a minimum echoic skill level. The preference assessments identified four highly preferred stimuli for each participant. Once the participant finished the echoic probe and preference assessments, he or she was enrolled in an experiment.

\section{Echoic Probe}

An echoic probe was conducted with each participant prior to the start of experimental sessions to ensure that the participant was able to imitate two-syllable sounds. Prior to each echoic probe session, a brief multiple-stimulus-without-replacement (MSWO) preference assessment was conducted with seven edible items identified as preferred by the participant's teacher (DeLeon \& Iwata, 1996). During the brief MSWO, the therapist asked the child to select an item from an array of seven edibles and allowed the child to consume the selected item. The therapist rotated the position of the remaining items and provided a directive for the participant to select another item. These procedures continued until all the items were selected or until the participant refused to select any additional items. Refusal to select an item was defined as the participant vocally stating "no" or the absence of a selection within $20 \mathrm{~s}$ of a prompt. The 
therapist blocked any attempts to select more than one item simultaneously, rearranged the items in the array, and then prompted the participant to select one item. The first two items the participant selected during the brief MSWO were used during the echoic probe.

During the echoic probe sessions, the therapist instructed the participant to repeat what she stated (refer to Appendix A for protocol and nonsense words). The therapist presented 10 trials consisting of two-syllable nonsense words during each session. The nonsense words contained the same sounds of potential target mands, but were rearranged into different combinations. If the participant correctly imitated the word, a small edible was delivered immediately. If the participant imitated incorrectly or failed to imitate the word within $10 \mathrm{~s}$, the therapist refrained from commenting and moved on to the next trial (no correction procedure was used). A total of three sessions were conducted across at least two days. All participants correctly imitated at least $80 \%$ of the words during each session and proceeded to the series of preference assessments outlined below.

\section{Preference Assessments}

Four sets of six toys were evaluated with each participant. Each set included a variety of toys from different sensory modalities (e.g., toys that made noise or music, toys with lights, action toys, small games, and tactile toys). The participants' teachers were interviewed to identify any toys the participant accessed in the classroom. Any toys identified by the teacher were not included in the sets of toys for that participant. The therapist asked the teacher to restrict access to similar toys in the classroom.

An MSWO preference assessment was conducted with each set of toys (DeLeon \& Iwata, 1996). Six toys were presented in an array to the participant. The therapist prompted the participant to select an item out of the array of toys. The participant was allowed to manipulate 
the selected item for $30 \mathrm{~s}$. The selected item was removed, the position of the remaining items rotated, and then the participant was given a directive to select another item. These procedures continued until all the items were selected or until the participant refused to select any additional items. Refusal to select an item was defined as the participant vocally stating "no" or the absence of a selection within $20 \mathrm{~s}$ of a directive to "pick one." The therapist prevented the participant from selecting more than one item simultaneously and prompted the participant to select one item. Once a block of the MSWO assessment was completed (i.e., all items were selected or the participant refused to select an item), all items were replaced and the procedures were repeated. This continued until six blocks of the MSWO assessment were completed with one set of toys. These procedures were repeated with a new set of toys until all four sets of toys were evaluated.

The number of times the item was selected was divided by the number of times the item was presented and then multiplied by 100 to obtain a percentage. The highest preferred toy was identified as the toy with the greatest percentage. The highest preferred toy from each set was one of the target toys and assigned a two-syllable nonsense name drawn from a list of words created prior to the study.

An MSWO assessment was conducted with the four highest preferred toys (one from each set) to evaluate if the toys were similarly preferred. Four blocks of the MSWO assessment were conducted. If the items were selected in different orders during each block, this was used as evidence that the preference for these toys was approximately equal and each toy was randomly assigned to an integrity level. This occurred for one of the six participants (Isaac). If the same toy was always selected first or last, this indicated that the participant's preference for these toys may not be approximately equal. This occurred for five of the six participants. In this 
case, the toys were conservatively assigned to an integrity level. If a toy was consistently selected first, it was assigned to a low integrity level (0\% or $40 \%)$. If a toy was consistently selected last, it was assigned to a high integrity level (70\% or $100 \%)$. These conservative assignments helped to prevent faster acquisition in a high-integrity condition because the toy was more preferred. Instead, the conservative assignments may have increased the likelihood of slower acquisition in the $100 \%$ or $70 \%$ integrity condition because the toy was less preferred.

\section{Experiment 1: Incorrect Item Delivery}

\section{Method}

Participants and Setting. Three children with developmental disabilities, Miles, Paige, and Isaac, participated. Miles was an 8-year-old male diagnosed with AttentionDeficit/Hyperactivity Disorder (ADHD), Oppositional-Defiant Disorder, and Asperger's Syndrome. Paige was a 7-year-old female diagnosed with Down Syndrome. Isaac was a 6-yearold male diagnosed with autism. All participants communicated vocally using full sentences. All participants emitted some independent mands, but had delayed mand repertoires. Teachers or parents reported that the participants engaged in problem behavior to access social reinforcers instead of using appropriate mands to access those reinforcers.

Each session consisted of 10, 60-s trials. Appointments were scheduled at least twice weekly with two to five sessions conducted during each appointment. Sessions were conducted in a quiet area of Miles' classroom and in a small room in Paige and Isaac's school.

Data Collection and Interobserver Agreement. Data were collected on the occurrence of correct independent and prompted mands, incorrect independent and prompted mands, or no response during each trial. A correct target mand was an independent or prompted vocalization consisting of the two-syllable name assigned to the target item. An incorrect mand was an 
independent or prompted vocalization that inaccurately identified the target item, including when the participant emitted the target mand within $2 \mathrm{~s}$ of another sound or word. The therapist transcribed the first vocal response emitted by the participant. An independent target mand was a request before the delivery of any prompts or following the "What do you want?" prompt level (refer to Training section for prompt definitions). A prompted target mand was a request following a partial or full prompt. The number of independent target mands was divided by 10 (total number of trials) and then converted into a percentage to provide participant performance during each session. The therapist also collected data on the toy delivered during each trial (refer to Appendix B).

The therapist trained graduate and undergraduate students on data-collection procedures. During training, the therapist reviewed the data-collection sheet and definitions with the trainee. The trainee and therapist simultaneously collected data on participant behavior during a session. Following the session, the therapist reviewed the trainee's data and provided feedback to the trainee. Feedback included praise for data collected accurately and constructive feedback on errors. To be considered trained, the trainee had to obtain at least $90 \%$ interobserver agreement (IOA) with the therapist across three consecutive training sessions.

Interobserver agreement was calculated by comparing each observer's record for each component on a trial-by-trial basis to determine agreement on the initial response, target response, and item delivered. For each component, the number of agreements was divided by agreements plus disagreements and converted into a percentage for each session. For example, if observer 1 recorded a $+,+\mathrm{NS},-,+,-\mathrm{NS}$ on the initial response and observer 2 recorded $\mathrm{a}+,+\mathrm{NS}$, ,,$-++\mathrm{PV}$ on the initial response, this would be scored as four agreements and one disagreement for this component. Four would be divided by five to provide a percentage of $80 \%$ agreement. 
The therapist and trained graduate and undergraduate students simultaneously and independently collected data on child behavior. Overall IOA for each participant was determined by averaging obtained session percentages across all sessions. Interobserver agreement was obtained for at least $33 \%$ of sessions for Miles, Paige, and Isaac. Mean IOA averaged above $95 \%$ for the prompt required for the initial response, prompt required for the target response, and item delivered across all participants (refer to Table 1 for obtained IOA).

Treatment fidelity data was obtained on the therapist gaining student attention, following the prompt hierarchy, and delivery of items, including which item was delivered and the time the item was delivered in relation to the mand (i.e., if the mand was delivered immediately following the request or independent of a request). Treatment fidelity coefficients were calculated by dividing the number of opportunities in which the target therapist behavior was performed correctly by the total number of opportunities in a session; this fraction was then converted into a percentage. During integrity error conditions, correct therapist behavior was determined according to a predetermined sequence (refer to Appendix C) the therapist was expected to follow during each session (see section on Treatment Integrity for additional details). Treatment fidelity was collected on $25.1 \%$ of sessions and averaged $99.5 \%$ (range, $93.3 \%$ to $100 \%$ ) across all participants.

Experimental Design. Four levels of treatment integrity $(0 \%, 40 \%, 70 \%$, and $100 \%)$ were evaluated using a multielement design embedded in a multiple-baseline-across-participants design. A multiple-baseline design involved the implementation of the independent variable (mand training) in a time-staggered sequence across three participants. A multielement design was used to compare the effects of the four levels of treatment integrity within participants. Four conditions (the four treatment integrity levels) were alternated randomly without replacement 
Table 1

Summary of Interobserver Agreement

\begin{tabular}{|c|c|c|c|c|c|c|c|}
\hline \multirow[t]{2}{*}{ Participant } & \multirow{2}{*}{$\begin{array}{l}\text { Percentage } \\
\text { of sessions }\end{array}$} & \multicolumn{2}{|c|}{$\begin{array}{l}\text { Prompt required for } \\
\text { initial response }\end{array}$} & \multicolumn{2}{|c|}{$\begin{array}{l}\text { Prompt required for } \\
\text { target response }\end{array}$} & \multicolumn{2}{|c|}{ Item delivered } \\
\hline & & $\mathrm{M}$ & Range & $\mathrm{M}$ & Range & $\mathrm{M}$ & Range \\
\hline \multicolumn{8}{|c|}{ Experiment 1} \\
\hline Miles & $33 \%$ & $96.7 \%$ & $70-100 \%$ & $97.4 \%$ & $70-100 \%$ & $100 \%$ & $100 \%$ \\
\hline Paige & $46.2 \%$ & $98 \%$ & $80-100 \%$ & $96 \%$ & $70-100 \%$ & $100 \%$ & $100 \%$ \\
\hline Isaac & $47 \%$ & $99 \%$ & $90-100 \%$ & $97.7 \%$ & $90-100 \%$ & $99.7 \%$ & $90-100 \%$ \\
\hline \multicolumn{8}{|c|}{ Experiment 2} \\
\hline Keith & $45.5 \%$ & $96 \%$ & $70-100 \%$ & $96.5 \%$ & $80-100 \%$ & N/A & N/A \\
\hline Mitch & $33.4 \%$ & $98.8 \%$ & $90-100 \%$ & $98.4 \%$ & $90-100 \%$ & N/A & N/A \\
\hline Logan & $33.3 \%$ & $96.5 \%$ & $70-100 \%$ & $99.7 \%$ & $90-100 \%$ & N/A & N/A \\
\hline
\end{tabular}


during baseline and training. Each condition included one target toy that was identified through the MSWO preference assessment.

Baseline. Before beginning each trial, the therapist obtained the participant's attention (defined as the participant orienting towards the therapist and looking towards the target item) by stating "[Name], look" while holding the target item in her hands. If the child did not attend to the initial directive, the therapist stated, "[Name], ready? Look." The therapist restated this directive every $5 \mathrm{~s}$ until she obtained the participant's attention. Then the therapist placed the target item in a clear container with the five other toys associated with the target toy's preference assessment set. The container was placed on the floor out of the participant's reach. The 60-s trial started as soon as the lid was placed on the container. If the participant did not emit the target mand after $10 \mathrm{~s}$, the therapist stated, "What do you want?" The therapist did not provide the participant with the correct nonsense name at any point during baseline.

If the participant had emitted the target mand during baseline sessions, the therapist would have delivered the item for the remainder of the trial; however, this never occurred. If the participant emitted the target name assigned to another item, any response other than the target mand, or did not emit a response, the therapist refrained from commenting and waited until the end of the 60-s trial before starting a new trial. Any other behavior was ignored or neutrally blocked (e.g., the participant attempting to leave the designated area in his classroom).

Training. During training sessions, the nonsense name for the target item was taught according to the assigned integrity level $(0 \%, 40 \%, 70 \%$, and $100 \%)$. The same prompting procedures were used during full trials and error trials. The therapist obtained the participant's attention as in baseline and then placed the target item in a clear container with the five other toys associated with the target toy's preference assessment set. The container was placed on the 
floor out of the participant's reach. The 60-s trial started when the lid was placed on the container. If the participant emitted the correct mand (prompted or unprompted) at any point during the trial, the therapist delivered the target item (full trials) or an unmatched item (error trials; discussed in Treatment Integrity Errors section) for the remaining duration of the trial.

The therapist followed a least-to-most prompting hierarchy (nonspecific prompt, partial prompt, and full prompt) during training trials. If the participant did not emit the target mand after $10 \mathrm{~s}$ from the start of the trial, the therapist stated, "What do you want?" (nonspecific prompt). If the target mand was not emitted within $10 \mathrm{~s}$ following the nonspecific prompt, the therapist stated the first syllable of the target response by stating "What do you want? Say [first syllable]" (partial prompt). For example, if the target response was meepo, then a partial prompt would consist of the therapist stating, "What do you want? Say mee." If the participant emitted the full target response (meepo), the toy was delivered. If the target mand was not emitted within $10 \mathrm{~s}$ following the partial prompt, the therapist modeled the entire response by stating "What do you want? Say [target mand]" (full prompt). For example, the therapist would state, "What do you want? Say meepo," if the target response was meepo. If the participant failed to emit the target mand following the full prompt, the therapist redelivered the full prompt every $10 \mathrm{~s}$ (at second 40 and second 50 during the trial) until the participant emitted the mand or the 60-s trial elapsed.

Non-targeted mands and other vocal statements (e.g., asking for the item by another name, requesting items outside of the experimental context, making statements about the items) did not have any programmed consequences during training. If a non-target mand or other vocal statement occurred, the therapist refrained from commenting and recorded an error for that trial. The therapist continued to follow the prompt hierarchy as scheduled until the 60-s trial elapsed 
or the target mand occurred. If the participant engaged in appropriate play behavior directed towards the therapist after the participant was given the toy, the therapist responded to or played with the participant for $5 \mathrm{~s}$ or until the trial ended, whichever came first.

Training sessions were conducted in each condition (integrity level) until the participant met either the mastery criterion or training-termination criterion. Each condition was terminated independently by meeting one of these criteria even though training continued in other conditions. Mastery occurred when the participant independently engaged in the target mand on at least $90 \%$ of trials across three consecutive sessions for that item. If mastery was not obtained during a condition, training was discontinued once at least 10 training sessions were conducted and visual inspection indicated that responding remained stable or decreased over at least the last six sessions. If a condition met the aforementioned criteria, training was terminated without the participant meeting mastery criterion.

Because mastered conditions were discontinued, the density of training for the remaining conditions increased (i.e., any one condition occurred more often). This may have increased the rate at which participants acquired the remaining conditions. Discontinuation of mastered conditions is consistent with previous literature (e.g., Bancroft, Weiss, Libby, \& Ahearn, 2011; Grow, Carr, Kodak, Jostad, \& Kisamore, 2011). Additionally, discontinuation of mastered conditions allowed for all skills to be taught in sessions as acquisition tasks. Interspersal of mastered skills may increase the rate at which target skills are acquired (Neef, Iwata, \& Page, 1980). Furthermore, some children prefer teaching that involves interspersed presentation of mastered skills with acquisition skills over teaching that only involves acquisition skills (Gary \& Dalenberg, 2005; Rhymer \& Morgan, 2005). Including the mastered conditions may have changed the environment of the sessions and made sessions more highly preferred. 
Treatment Integrity Errors. Ten predetermined sequences were created that specified which of the 10 trials were correctly implemented (full integrity; discussed in Training section) and which trials involved an error (refer to Appendix C). Each predetermined sequence consisted of 10 trials that outlined the order of the trials so that either $40 \%$ or $70 \%$ of the trials were implemented correctly (e.g., a 70\% integrity predetermined sequence consisted of seven trials that were conducted correctly and three error trials). The therapist shuffled the predetermined sequences for a given integrity level and randomly selected a predetermined sequence to follow before beginning each session. Following selection, the predetermined sequence was not replaced. Prior to the next session, another predetermined sequence was selected from the remaining nine. This continued until all the predetermined sequences had been used. Then, all 10 predetermined sequences were replaced and the process was repeated.

Treatment integrity errors consisted of delivering an incorrect item (i.e., an item that did not correspond to the target mand) following the occurrence of a target mand. Least-to-most prompting (nonspecific, partial, and full prompt; outlined in Training) was used to prompt the target mand during error trials. During an error trial, the therapist randomly selected a toy that was not assigned to the target mand from the container by reaching into the container and pulling out the first non-target toy that she touched. If the first toy the therapist came into contact with was the target item, that item was replaced and another item selected. The randomly selected item was delivered to the participant following the target mand. The participant had access to the delivered item for the remainder of the trial.

During the $0 \%$ integrity condition, an incorrect item (a non-target item) was delivered following the target mand for all 10 trials. During the $40 \%$ integrity condition, the correct item (matched to the mand) was delivered for four trials, and an incorrect item was delivered 
following the target mand for six trials. During the $70 \%$ integrity condition, the correct item was delivered immediately following the mand for seven trials and an incorrect item was delivered following the target mand for three trials. During the $100 \%$ integrity condition, the correct item was delivered immediately following the mand for all 10 trials.

Modified Prompting (Isaac only). Modified prompting consisted of more intensive mand-training procedures that simulated how mand training may occur in the natural environment. Modified prompting was introduced when levels of independent target mands remained low across all integrity conditions after at least 10 sessions in each condition during the standard training. Isaac was the only participant to meet this criterion.

During the modified prompting procedures, training continued as outlined in the Training and Treatment Integrity Errors sections with two modifications. First, if Isaac did not emit the target mand within $10 \mathrm{~s}$, the therapist removed the target item from the container. The therapist held the target item in front of Isaac and stated the nonspecific prompt ("What do you want?"). The therapist continued to hold the target item in front of Isaac as she progressed through the prompting hierarchy until he emitted the target mand or the 60 -s trial elapsed. Second, the delivery of the item was paired with a descriptive praise statement (e.g., "Nice job asking for [nonsense word]."). During full trials, the descriptive praise statement included the target response. During error trials, the target toy was placed back in the box and the therapist randomly selected a non-target item that was delivered to Isaac. The descriptive praise statement included a nonsense word that was paired with the specific non-target item (refer to Table 2). For example, if the therapist selected the phone, the praise statement would be, "Nice job asking for smeehoon." 
Table 2

Non-target Items and Assigned Nonsense Names for Isaac

\begin{tabular}{ccc}
\hline Condition & Non-target Toy & Assigned Name \\
\hline $0 \%$ & Drum & Mib/eeps \\
$0 \%$ & Bubbles & Mib/feen \\
$0 \%$ & Cooties $^{\mathrm{TM}}$ & Mib/biss \\
$0 \%$ & Sketch board & Pag/ooth \\
$0 \%$ & Dinosaurs & Leet/ooth \\
$40 \%$ & Moon sand & Fide/noop \\
$40 \%$ & Camera & Fide/ips \\
$40 \%$ & Mr. Potato Head & Foo/boop \\
$40 \%$ & Pipe cleaners & Dite/boop \\
$40 \%$ & Monkeys & Rine/boop \\
$70 \%$ & Peg board & Smee/tooce \\
$70 \%$ & Phone & Smee/hoon \\
$70 \%$ & Police car & Smee/choid \\
$70 \%$ & K'Nex & Dat/poom \\
$70 \%$ & Action figures & Gree/poom \\
\hline
\end{tabular}




\section{Results}

Figure 1 shows the outcomes of the series of four MSWO preference assessments for Miles. Miles' highly preferred items were Yak-back ${ }^{\mathrm{TM}}$ (Set A; top panel), fishing game (Set B; second panel), truck (Set C; third panel), and recorder (Set D; bottom panel). The series of four MSWOs for Paige is depicted in Figure 2. Paige's highly preferred items were the camera (Set A; top panel), clock (Set B; second panel), baby (Set C; third panel), and sketch board (Set D; bottom panel). Figure 3 shows the series of the four MSWOs for Isaac. Isaac's highly preferred items were the cars (Set A; top panel), Hungry Hippos ${ }^{\text {TM }}$ (Set B; second panel), ball/wire toy (Set C; third panel), and Slinky ${ }^{\mathrm{TM}}$ (Set D; bottom panel). Each of these items were assigned a two-syllable nonsense name (refer to Table 3).

An MSWO preference assessment was conducted with the four highest preferred toys for each participant (data are shown in Figure 4). Miles (top panel) always selected the truck first and the fishing game third or last. Therefore, the truck was randomly assigned to a low integrity level and the fishing game to a high integrity level. The remaining items (recorder and Yakback $^{\mathrm{TM}}$ ) were randomly assigned to the two remaining integrity levels. For Miles, the fishing game was assigned to the $100 \%$ integrity condition, Yak-back ${ }^{\mathrm{TM}}$ to the $70 \%$ integrity condition, recorder to the $40 \%$ integrity condition, and the truck to the $0 \%$ integrity condition.

Paige always selected the clock first and the camera third or fourth (Figure 4, middle panel). Therefore, the clock was randomly assigned to a low integrity level and the camera to a high integrity level. The remaining items (sketch board and baby) were randomly assigned to the two remaining integrity levels. For Paige, the baby was assigned to the $100 \%$ integrity condition, camera to the $70 \%$ integrity condition, sketch board to the $40 \%$ integrity condition, and the clock to the $0 \%$ integrity condition. 

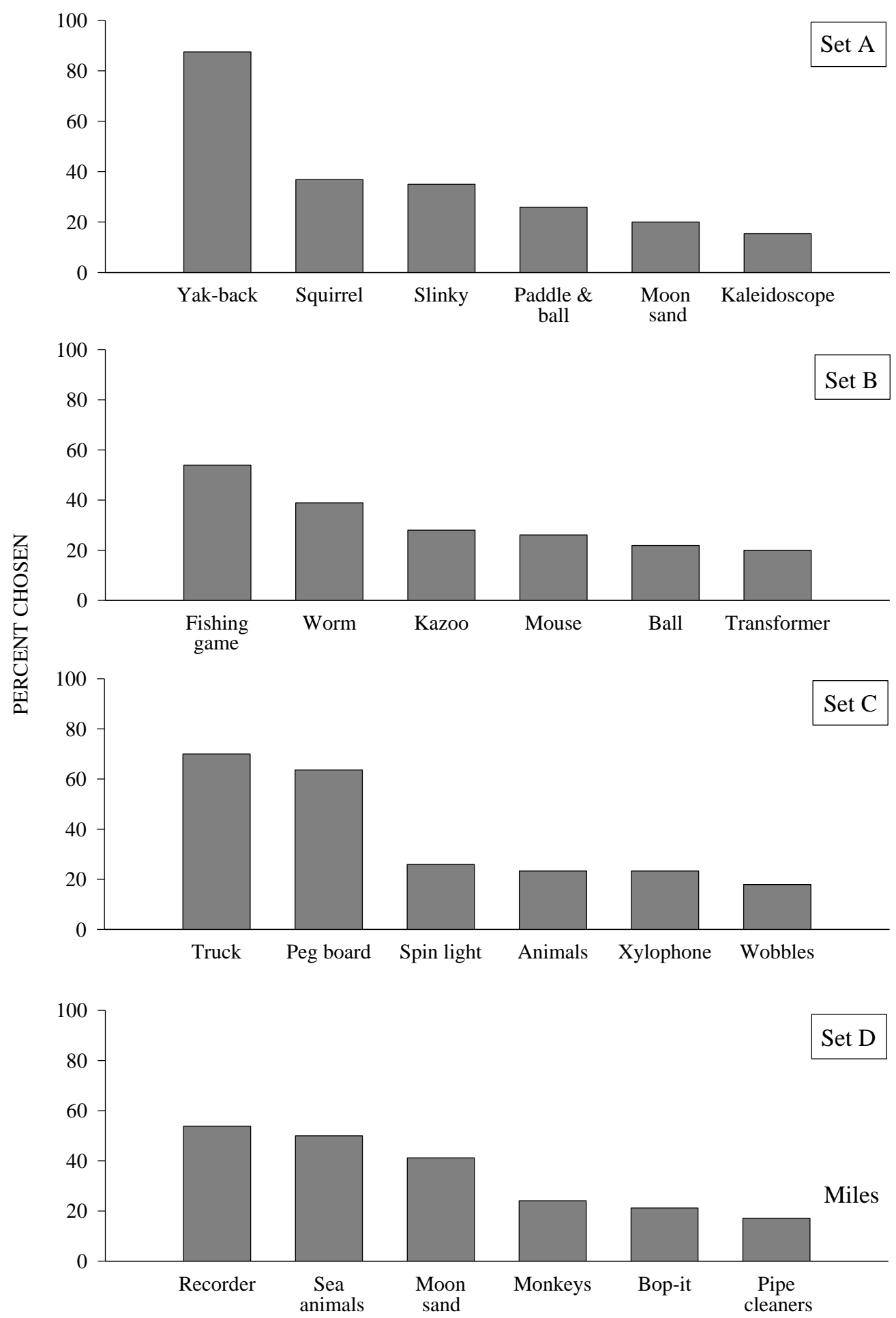

Figure 1: Percentage of opportunities on which a particular toy was selected during MSWO preference assessments across the four sets of toys for Miles. The highest preferred toys (items on the far left of each panel) were each assigned to an integrity level. 

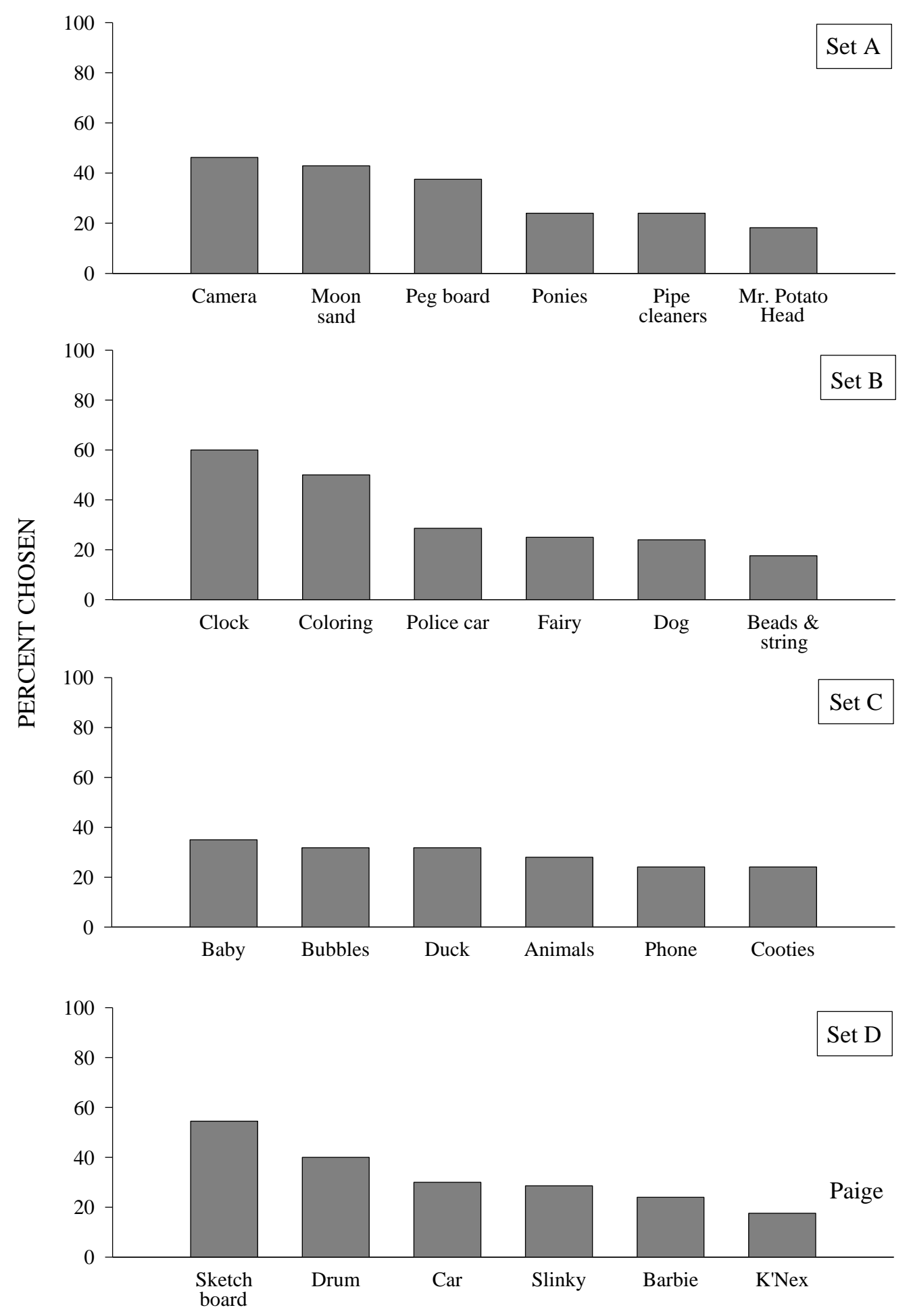

Figure 2: Percentage of opportunities on which a particular toy was selected during MSWO preference assessments across the four sets of toys for Paige. The highest preferred toys (items on the far left of each panel) were each assigned to an integrity level. 


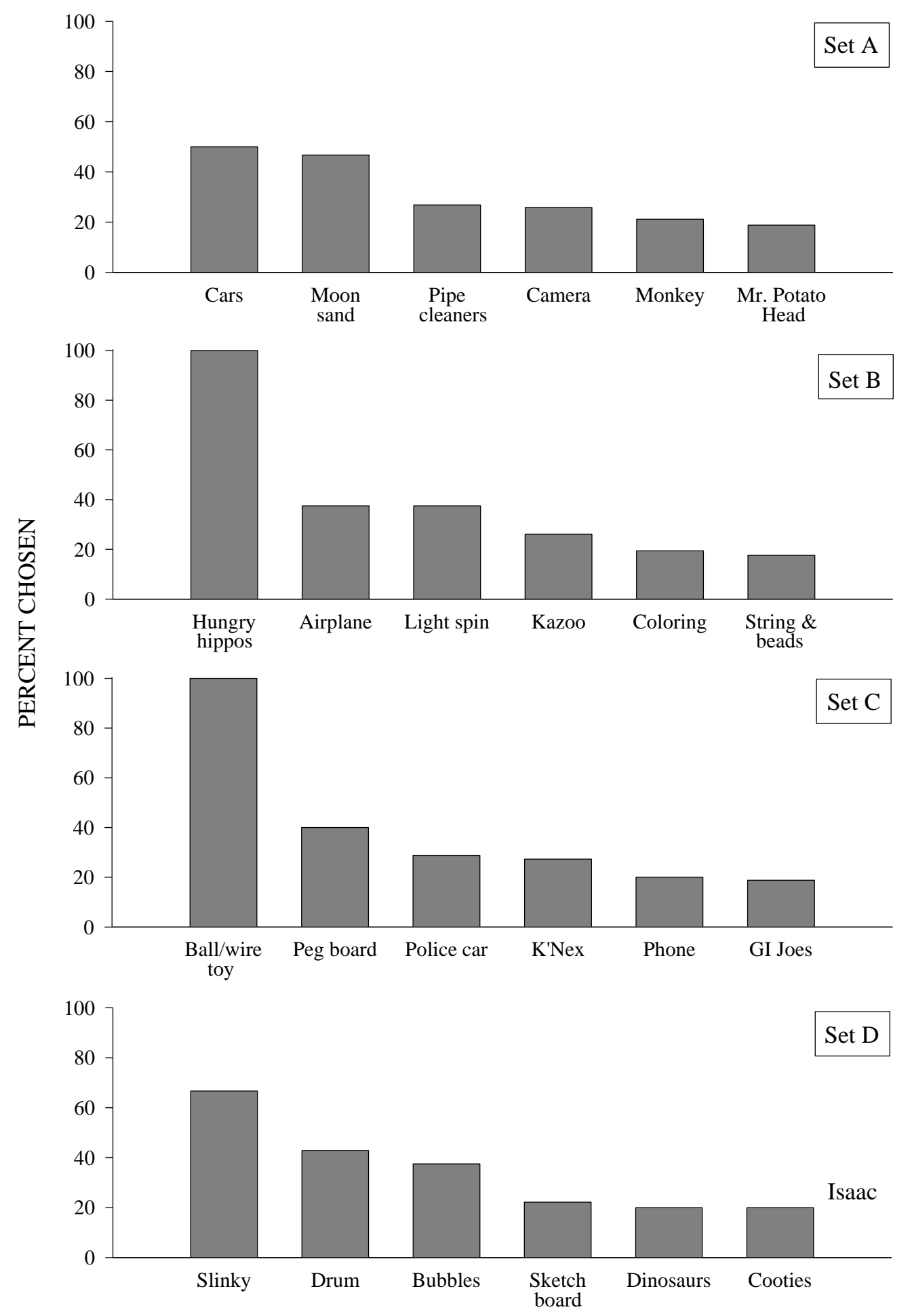

Figure 3: Percentage of opportunities on which a particular toy was selected during MSWO preference assessments across the four sets of toys for Isaac. The highest preferred toys (items on the far left of each panel) were each assigned to an integrity level. 
Table 3

Assigned Nonsense Names for Participants and Conditions

\begin{tabular}{|c|c|c|c|}
\hline & Condition & Toy & Assigned Name \\
\hline \multicolumn{4}{|c|}{ Experiment 1} \\
\hline \multirow[t]{4}{*}{ Miles } & $0 \%$ & Truck & Tazz/choid \\
\hline & $40 \%$ & Recorder & Fide/zeet \\
\hline & $70 \%$ & Yak-back $^{\mathrm{TM}}$ & Mib/ooth \\
\hline & $100 \%$ & Fishing game & Slee/tooce \\
\hline \multirow[t]{4}{*}{ Paige } & $0 \%$ & Clock & Tazz/choid \\
\hline & $40 \%$ & Sketch board & Smee/poom \\
\hline & $70 \%$ & Camera & Nass/doin \\
\hline & $100 \%$ & Baby & Fide/zeet \\
\hline \multirow[t]{4}{*}{ Isaac } & $0 \%$ & Slinky ${ }^{\mathrm{TM}}$ & Mib/ooth \\
\hline & $40 \%$ & Cars & Fide/boop \\
\hline & $70 \%$ & Ball/wire toy & Smee/poom \\
\hline & $100 \%$ & Hungry Hippo ${ }^{\mathrm{TM}}$ & Nass/doin \\
\hline \multicolumn{4}{|c|}{ Experiment 2} \\
\hline \multirow[t]{4}{*}{ Keith } & $0 \%$ & Sticky hands & Pif/eeps \\
\hline & $40 \%$ & Transformer ${ }^{\mathrm{TM}}$ & Smee/poom \\
\hline & $70 \%$ & Bubbles & Nass/doin \\
\hline & $100 \%$ & Airplane & Zipe/reen \\
\hline \multirow[t]{4}{*}{ Mitch } & $0 \%$ & Slinky ${ }^{\mathrm{TM}}$ & Chid/ips \\
\hline & $40 \%$ & Etch-A-Sketch TM & Dat/thoin \\
\hline & $70 \%$ & Animals & Gree/hoon \\
\hline & $100 \%$ & Fishing game & Rine/leet \\
\hline \multirow[t]{4}{*}{ Logan } & $0 \%$ & Bop-It ${ }^{\mathrm{TM}}$ & Zipe/reen \\
\hline & $40 \%$ & Yak-back $^{\mathrm{TM}}$ & Dite/meeg \\
\hline & $70 \%$ & GI Joe ${ }^{\mathrm{TM}}$ & Biss/anth \\
\hline & $100 \%$ & Animals & Smee/poom \\
\hline
\end{tabular}



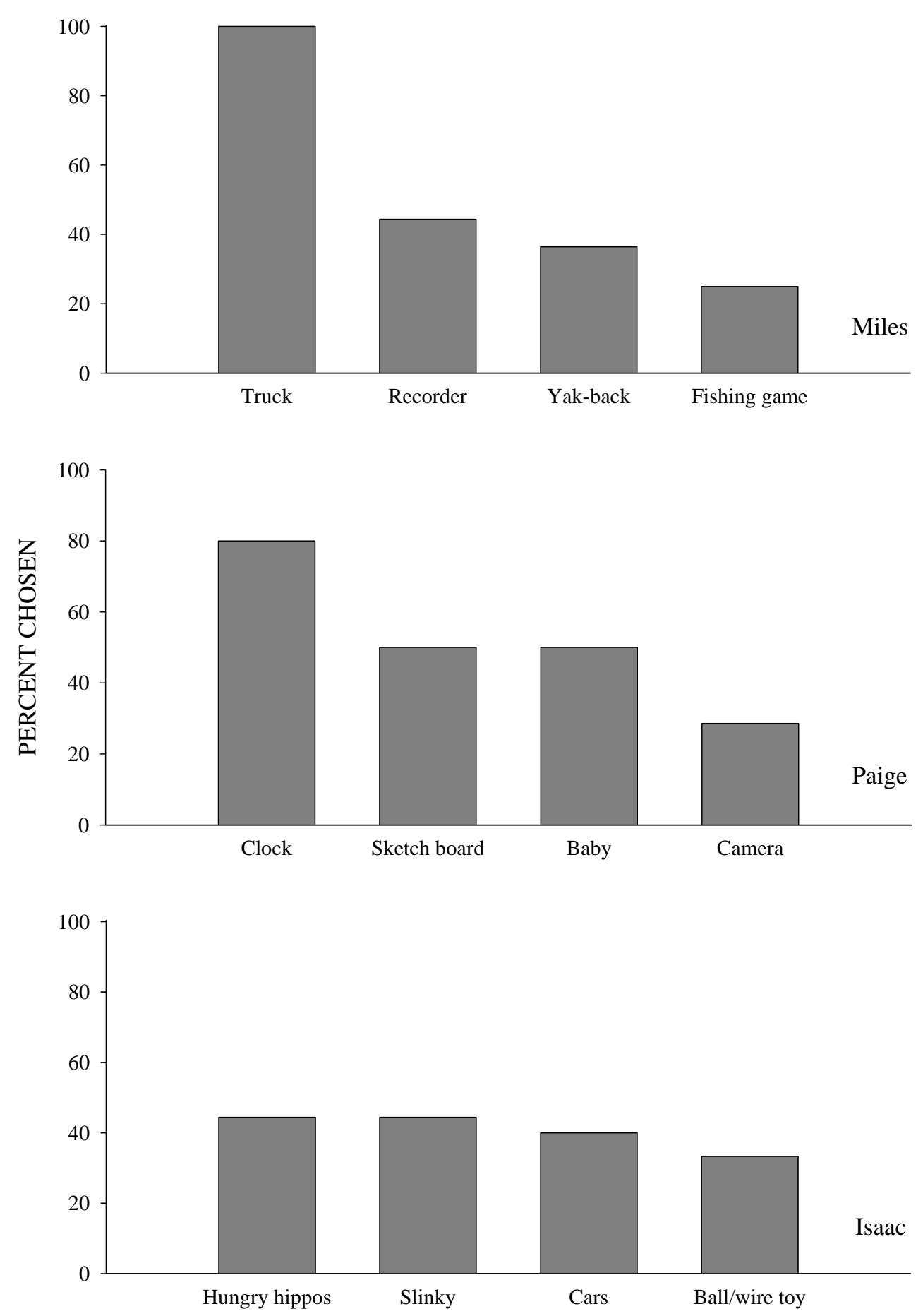

Figure 4: Percentage of opportunities on which a particular toy was selected during MSWO preference assessment with the four highest preferred items from each set of toys for Miles (top panel), Paige (middle panel), and Isaac (bottom panel). 
Isaac selected the items approximately equally (Figure 4, bottom panel). Therefore, the items were randomly assigned to integrity conditions. For Isaac, the Hungry Hippos ${ }^{\mathrm{TM}}$ were assigned to the $100 \%$ integrity condition, ball/wire toy to the $70 \%$ integrity condition, cars to the $40 \%$ integrity condition, and the Slinky ${ }^{\mathrm{TM}}$ to the $0 \%$ integrity condition.

The percentage of independent target mands across baseline and training sessions for the four levels of treatment integrity are depicted in Figure 5. No independent target mands occurred for Miles, Paige, or Isaac during baseline. During training, Miles (top panel) engaged in variable levels of independent target mands across all conditions. Miles reached mastery criteria in the 100\% integrity condition first after 33 training sessions (refer to Table 4). Miles also met mastery criteria in the $0 \%$ integrity condition after 38 training sessions. Training was discontinued after 45 training sessions for the $40 \%$ and $70 \%$ integrity conditions. Levels of independent target mands averaged $58.3 \%$ across the last six sessions of training for the $40 \%$ integrity condition and $23.3 \%$ for the $70 \%$ integrity condition.

Paige engaged in variable levels of independent target mands across all conditions during training (middle panel, Figure 5). Paige met the mastery criterion during the $100 \%$ integrity condition after 10 training sessions (refer to Table 4). Paige mastered the mand during the $40 \%$ integrity condition after 19 training sessions. Paige met the mastery criterion in the $70 \%$ integrity condition after 24 training sessions. Training was discontinued in the $0 \%$ integrity condition after 24 training sessions. Levels of independent target mands averaged $0 \%$ across the last six sessions of training for the $0 \%$ integrity condition.

Isaac (bottom panel, Figure 5) engaged in low levels of independent target mands during training. Modified training was implemented after 10 sessions of training for each integrity condition. Although independent target mands occurred slightly more often during modified 


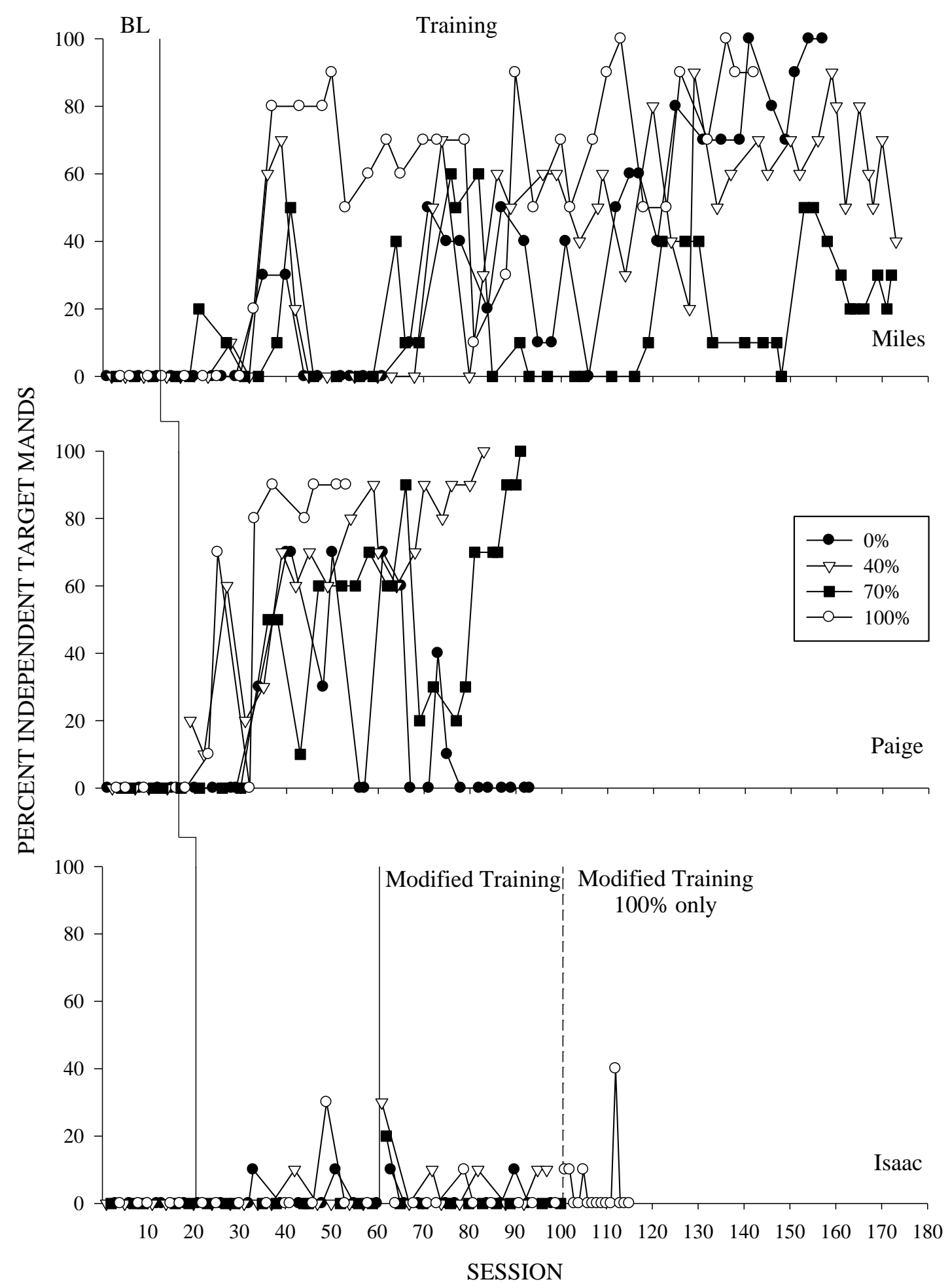

Figure 5: Percentage of correct independent mands with incorrect item delivery during 0\%, 40\%, 70\%, and 100\% integrity sessions across baseline and training for Miles (top panel), Paige (middle panel), and Isaac (bottom panel). 
Table 4

Summary of Independent Target Mands and Session Termination for Experiment 1

\begin{tabular}{ccccccc}
\hline Participant & Condition & $\begin{array}{c}\text { Number of } \\
\text { sessions to } \\
\text { termination }\end{array}$ & $\begin{array}{c}\text { Condition } \\
\text { mastered }\end{array}$ & $\begin{array}{c}\text { Mean correct } \\
\text { last 3 sessions }\end{array}$ & $\begin{array}{c}\text { Mean correct } \\
\text { last 6 sessions }\end{array}$ & $\begin{array}{c}\text { Mean } \\
\text { correct } \\
\text { overall }\end{array}$ \\
\hline Miles & $0 \%$ & 38 & Yes & $96.7 \%$ & $90 \%$ & $37.1 \%$ \\
& $40 \%$ & 45 & No & $53.3 \%$ & $58.3 \%$ & $42.4 \%$ \\
& $70 \%$ & 45 & No & $26.7 \%$ & $23.3 \%$ & $18 \%$ \\
& $100 \%$ & 33 & Yes & $93.3 \%$ & $81.7 \%$ & $57.6 \%$ \\
\hline Paige & $0 \%$ & 24 & No & $0 \%$ & $0 \%$ & $18.8 \%$ \\
& $40 \%$ & 19 & Yes & $93.3 \%$ & $86.7 \%$ & $64.2 \%$ \\
& $70 \%$ & 24 & Yes & $93.3 \%$ & $81.7 \%$ & $48.3 \%$ \\
& $100 \%$ & 10 & Yes & $90 \%$ & $86.7 \%$ & $60 \%$ \\
& $0 \%$ & 20 & No & $3.3 \%$ & $1.7 \%$ & $2 \%$ \\
& $40 \%$ & 20 & No & $6.7 \%$ & $5 \%$ & $4 \%$ \\
& $70 \%$ & 20 & No & $0 \%$ & $0 \%$ & $1 \%$ \\
& $100 \%$ & 35 & No & $0 \%$ & $6.7 \%$ & $3.1 \%$ \\
\hline
\end{tabular}


training, levels of independent target mands remained at low levels across all conditions. After a total of 20 training sessions (10 with standard training and 10 with modified training), training was discontinued in the $0 \%, 40 \%$, and $70 \%$ integrity conditions (refer to Table 4 ). To evaluate if interspersal of skills across the different conditions was impeding acquisition, training was continued in the $100 \%$ integrity condition. However, independent target mands remained at low levels for an additional 15 training sessions. Training was discontinued in the $100 \%$ integrity condition after a total of 35 training sessions.

\section{Discussion}

Only two of the three participants acquired mands during training. For these two participants (Miles and Paige), acquisition occurred with the fewest training sessions in the 100\% integrity condition, suggesting that delivery of the correct item (matched to the target mand) is important to acquisition.

Delivery of incorrect items was detrimental to acquisition; however, the effects were idiosyncratic across participants. Miles acquired the target mand during the $0 \%$ integrity condition, but Paige engaged in the lowest levels of independent target mands during this condition. For some individuals, acquisition may occur more quickly when either the item is consistently delivered (100\% integrity) or a variety of items are delivered following the mand ( $0 \%$ integrity). The arrangement in the $0 \%$ integrity condition may approximate the acquisition of a generalized mand in the natural environment. A generalized mand is a mand that is under the functional control of several different establishing operations and is maintained by the delivery of a variety of stimuli. For example, a child may engage in the response "more" to ask for several different stimuli in his environment, including items (bubbles, teddy bear, edibles) and actions (push, spin). For Miles, the mand acquired in the $0 \%$ integrity condition may have 
been a generalized mand. The mand trained in the $0 \%$ integrity condition occurred on $10.7 \%$ of trials (range, $0 \%$ to $40 \%$ ) of the last 15 session in the $40 \%$ condition. The mand occurred on $6.7 \%$ of trials (range, $0 \%$ to $40 \%$ ) across the last 15 sessions of the $70 \%$ integrity condition. The mand trained with $0 \%$ integrity may have been a generalized mand because the mand was maintained by the delivered of a variety of toys.

Acquisition was impeded for Miles when the target item was delivered inconsistently during $40 \%$ and $70 \%$ integrity conditions. Paige met mastery criteria during both the $40 \%$ and $70 \%$ integrity conditions with fewer training sessions required for mastery during the $40 \%$ integrity condition. Miles engaged in differentially higher levels of target mands during the $40 \%$ integrity condition than the $70 \%$ integrity condition. For Paige and Miles, the delivery of the incorrect item on $30 \%$ of trials (70\% integrity) was more detrimental to acquisition than the delivery of the incorrect item on $60 \%$ of trials ( $40 \%$ integrity). One potential reason for this finding is the conservative assignment of toys to each condition. For both participants, the item assigned to the $40 \%$ condition (recorder for Miles and sketch board for Paige) was selected at a higher percentage than the item assigned to the $70 \%$ condition (the Yak-back ${ }^{\mathrm{TM}}$ for Miles and the camera for Paige). Although the $40 \%$ item was delivered less often, it may have been a more potent reinforcer.

One participant, Isaac, did not acquire any mands during training or modified training. Isaac engaged in some problematic and inattentive behavior that may have interfered with his acquisition during training. For example, Isaac periodically refused to engage in a response or pretended to fall asleep during sessions and between sessions. However, data were not collected on rates of problem behavior, so the extent to which this behavior occurred during instructional trials remains unknown. 
Another possible reason for the lack of acquisition seen with Isaac is that the toys used did not function as reinforcers. However, Isaac frequently manipulated toys when toys were freely available and asked for toys in the classroom. It also appeared that toys functioned as reinforcers for appropriate behavior in the classroom. For example, Isaac completed academic work to gain access to toys, including trains, puzzles, and the computer in his special education classroom. It is possible that toys functioned as reinforcers in this context, but did not function as reinforcers when delivered contingent on a vocal response. It is also possible that restricting access to toys did not create an establishing operation for Isaac. In the absence of an establishing operation, Isaac may have been unmotivated to engage in the response, thus impeding acquisition. The lack of acquisition does not appear to be an effect of satiation (decreases in behavior are observed as the result of continued contact with the toy). Higher levels of correct responding should have been observed in the $0 \%$ integrity compared to the other conditions or performance should have decreased within session if Isaac quickly satiated on toys. However, this was not observed.

Given that Isaac entered the study with some independent mands in his repertoire, it is likely that idiosyncratic variables in the natural environment are important for Isaac to acquire mands and that these variables were not simulated in the experimental sessions. Establishing operations might be created by having Isaac complete work for a duration of time before providing an opportunity to mand. For example, in the classroom, not only are toys restricted, but Isaac is also required to complete an academic task before access to toys is provided. A combination of restricted access and work requirements may have increased the establishing operation for access to toys and the likelihood that Isaac would mand. Alternatively, a most-toleast prompting hierarchy with systematic fading of prompts may be more effective than the 
least-to-most prompting procedures used in this study. A most-to-least prompting procedure would include the immediate full model of the correct response and reduce the likelihood that Isaac would engage in incorrect responses. As Isaac continued to engage in correct responses with the prompt, the prompt would be faded to the partial prompt (first syllable of word) and then nonspecific prompt. The least-to-most prompting used in this study allowed Isaac to make errors before prompts were delivered. It is possible that an error history was created that impeded acquisition and that may have been prevented with a different prompting hierarchy.

Delivery of the item that is matched to the mand (e.g., delivering chips when the child says "chips") is an important component to mand acquisition. Because occasional errors (70\% integrity) were detrimental to acquisition for both participants, mand training must involve consistent matched item delivery for children to acquire mands with the least amount of training. This suggests that caregivers should ensure that another item (even if highly preferred) is not delivered following a mand. When the child asks for an item that is unavailable (e.g., a McDonald's hamburger in the middle of the school day), caregivers should refrain from delivering an unmatched item that is available (e.g., chips or an apple). Additionally, if a child has articulation issues that result in caregivers being unable to understand mands, caregivers should consider having the child use a topography of manding that can be more easily understood (e.g., picture-exchange system or signs) and thus, consistently reinforced.

\section{Experiment 2: Response-Independent Item Delivery}

\section{Method}

Participants and Setting. Three children, Keith, Logan, and Mitch, participated. Keith was a 6-year-old male diagnosed with traumatic brain injury. Logan was an 8-year old male diagnosed with ADHD and Post-Traumatic Stress Disorder. Mitch was a 7-year-old male 
diagnosed with Pervasive Developmental Disorder-Not Otherwise Specified (PDD-NOS).

Keith, Logan, and Mitch communicated vocally using full sentences. All participants engaged in some independent mands, but had delayed mand repertoires. Teachers or parents reported that the participants engaged in problem behavior to access social reinforcers instead of using appropriate mands to access those reinforcers. Appointments were scheduled at least twice weekly with two to five sessions conducted per appointment. Sessions were conducted in a small classroom in Keith's school and in a quiet area of Logan and Mitch's classroom.

Data Collection and Interobserver Agreement. Data were collected on the occurrence of correct independent and prompted mands, incorrect independent and prompted mands, or no response during each trial as outlined in Experiment 1. Data were also collected on whether the initial response occurred before or after toy delivery during error trials (refer to Appendix D for data collection sheet).

Interobserver agreement was calculated as described in Experiment 1, except IOA was not obtained on the item delivered. Interobserver agreement was obtained on at least $33.3 \%$ of sessions for Keith, Mitch, and Logan. Mean IOA averaged above 95\% for the prompt required for the initial response and for the prompt required for the target response across all participants (refer to Table 1).

Treatment fidelity data were obtained as outlined in Experiment 1 . Treatment fidelity was collected on $25.7 \%$ of sessions and averaged $99.8 \%$ (range, $94.1 \%$ to $100 \%$ ) across all participants.

Baseline. Baseline sessions were conducted as outlined in Experiment 1, except that only the target toy was present in the clear container during all trials. 
Training. Training sessions were conducted as outlined in Experiment 1, except that only the target toy was present in the clear container during all trials.

Treatment Integrity Errors. The same predetermined sequences created for Experiment 1 were used to specify which of the 10 trials were correctly implemented and which trials involved an error at the prescribed integrity level. Full trials followed the least-to-most prompting training procedure and the item was delivered immediately following a correct response.

Treatment integrity errors consisted of delivering the target item, independent of responding, $5 \mathrm{~s}$ after the trial began. During an error trial, the therapist obtained the participant's attention, placed the target item in a clear container, and placed the container on the floor out of the participant's reach. The therapist started the trial once the lid was placed on the container. The participant was not required to emit a response for the target toy to be delivered. The therapist delivered the target item to the participant $5 \mathrm{~s}$ after the trial began, and no prompts were delivered. The participant was provided access to the toy for the remainder of the trial. If the participant engaged in an incorrect or correct response before the delivery of the item during a trial in which an error was scheduled, the therapist refrained from commenting, recorded the response, and delivered the item as scheduled.

During the $0 \%$ integrity condition, the target item was delivered $5 \mathrm{~s}$ after the trial began (regardless of responding) for all 10 trials. During the $40 \%$ integrity condition, the target item was delivered immediately following the mand for four trials and was delivered $5 \mathrm{~s}$ after the trial began on six trials. During the $70 \%$ integrity condition, the target item was delivered immediately following the mand for seven trials and $5 \mathrm{~s}$ after the trial began for three trials. 
During the $100 \%$ integrity condition, the target item was delivered immediately following the mand for all 10 trials.

Modified Prompting (Logan only). The criterion to move to modified prompting described in Experiment 1 was used during Experiment 2; modified prompting was introduced when levels of independent target mands remained low across all integrity conditions after at least 10 sessions in each condition during the standard training. Logan was the only participant to meet this criterion in Experiment 2.

During the modified prompting procedures, full trials were conducted as outlined in the training section with two modifications. First, if Logan did not emit the target mand within $10 \mathrm{~s}$, the therapist removed the target item from the container. The therapist held the target item in front of Logan and stated the nonspecific prompt ("What do you want?"). The therapist continued to hold the target item in front of Logan as she progressed through the prompting hierarchy until Logan emitted the target mand. Second, the delivery of the item was paired with a descriptive praise statement that contained the target mand (e.g., "Nice job asking for [target nonsense word]."). No modifications were made to the error trials.

\section{Results}

The outcomes of the four MSWO preference assessments for Keith are depicted in Figure 6. Keith's highly preferred items were sticky hand (Set A; top panel), Transformers ${ }^{\mathrm{TM}}$ (Set B; second panel), bubbles (Set C; third panel), and airplanes (Set D; bottom panel). The series of four MSWOs for Mitch are depicted in Figure 7. Mitch's highly preferred items were the animals (Set A; top panel), fishing game (Set B; second panel), Slinky ${ }^{\mathrm{TM}}$ (Set C; third panel), and Etch-A-Sketch ${ }^{\mathrm{TM}}$ (Set D; bottom panel). Figure 8 shows the series of the four MSWOs for Logan. Logan's highly preferred items were the Yak-back ${ }^{\mathrm{TM}}$ (Set A; top panel), Bop-It ${ }^{\mathrm{TM}}$ (Set 
B; second panel), animals (Set C; third panel), and GI Joes ${ }^{\mathrm{TM}}$ (Set D; bottom panel). Each of these items were assigned a two-syllable nonsense name (refer to Table 3).

A MSWO preference assessment was conducted with the four highest preferred toys for each participant (data are shown in Figure 9). Keith (top panel) always selected the sticky hands and the Transformers ${ }^{\mathrm{TM}}$ either first or second and the airplanes and bubbles either third or last. Therefore, the sticky hand and Transformers ${ }^{\mathrm{TM}}$ were randomly assigned to low integrity levels and the airplane and bubbles were randomly assigned to high integrity levels. For Keith, the airplanes were assigned to the $100 \%$ integrity condition, bubbles to the $70 \%$ integrity condition, Transformers ${ }^{\mathrm{TM}}$ to the $40 \%$ integrity condition, and the sticky hands to the $0 \%$ integrity condition.

Mitch selected the Slinky ${ }^{\mathrm{TM}}$ and Etch-A-Sketch ${ }^{\mathrm{TM}}$ before he selected the animals and fishing game (Figure 9, middle panel). Therefore, the Slinky ${ }^{\mathrm{TM}}$ and Etch-A-Sketch ${ }^{\mathrm{TM}}$ were randomly assigned low integrity levels and the animals and fishing game were randomly assigned to a high integrity levels. For Mitch, the fishing game was assigned to the $100 \%$ integrity condition, animals to the $70 \%$ integrity condition, Etch-A-Sketch ${ }^{\mathrm{TM}}$ to the $40 \%$ integrity condition, and the Slinky ${ }^{\mathrm{TM}}$ to the $0 \%$ integrity condition.

Logan always selected the Bop-It ${ }^{\mathrm{TM}}$ first; therefore, it was assigned to a low integrity level (Figure 9, bottom panel). Logan selected the GI Joes ${ }^{\mathrm{TM}}$ and animals third or last, and these items were assigned to high integrity levels. For Logan, the animals were assigned to the $100 \%$ integrity condition, GI Joes ${ }^{\mathrm{TM}}$ to the $70 \%$ integrity condition, Yak-back ${ }^{\mathrm{TM}}$ to the $40 \%$ integrity condition, and the Bop-It ${ }^{\mathrm{TM}}$ to the $0 \%$ integrity condition. 

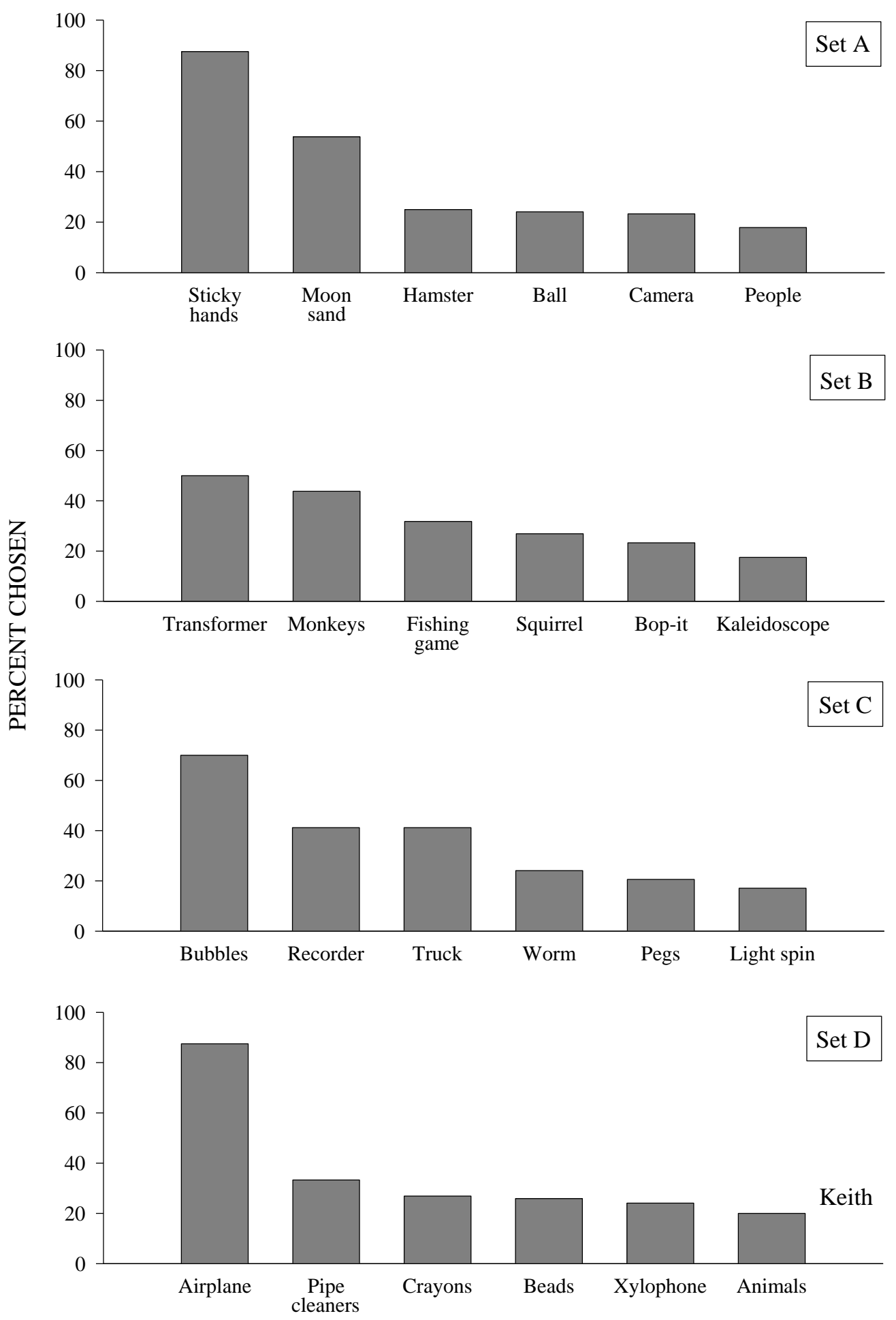

Figure 6: Percentage of opportunities on which a particular toy was selected during MSWO preference assessments across the four sets of toys for Keith. The highest preferred toys (items on the far left of each panel) were each assigned to an integrity level. 

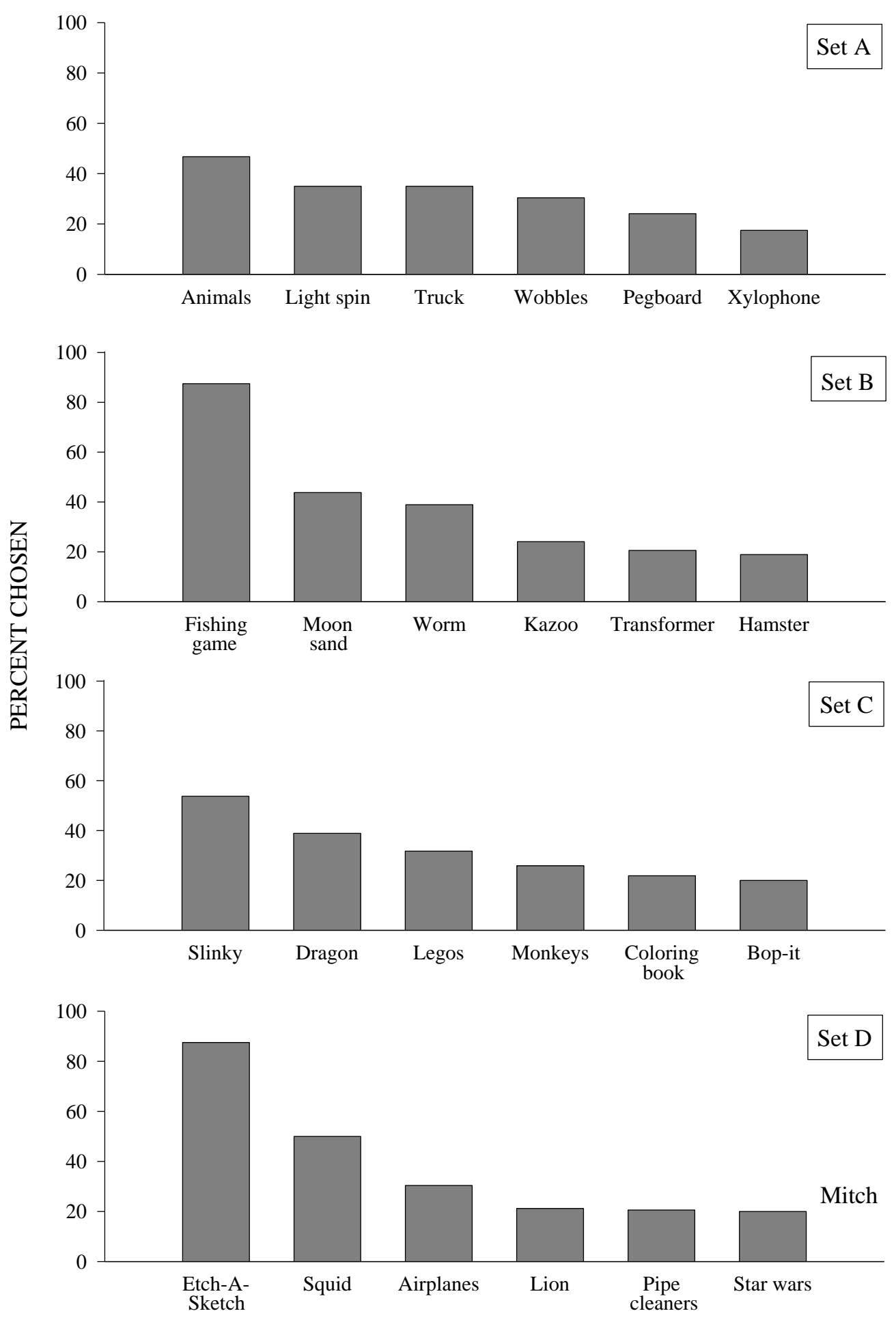

Figure 7: Percentage of opportunities on which a particular toy was selected during MSWO preference assessments across the four sets of toys for Mitch. The highest preferred toys (items on the far left of each panel) were each assigned to an integrity level. 


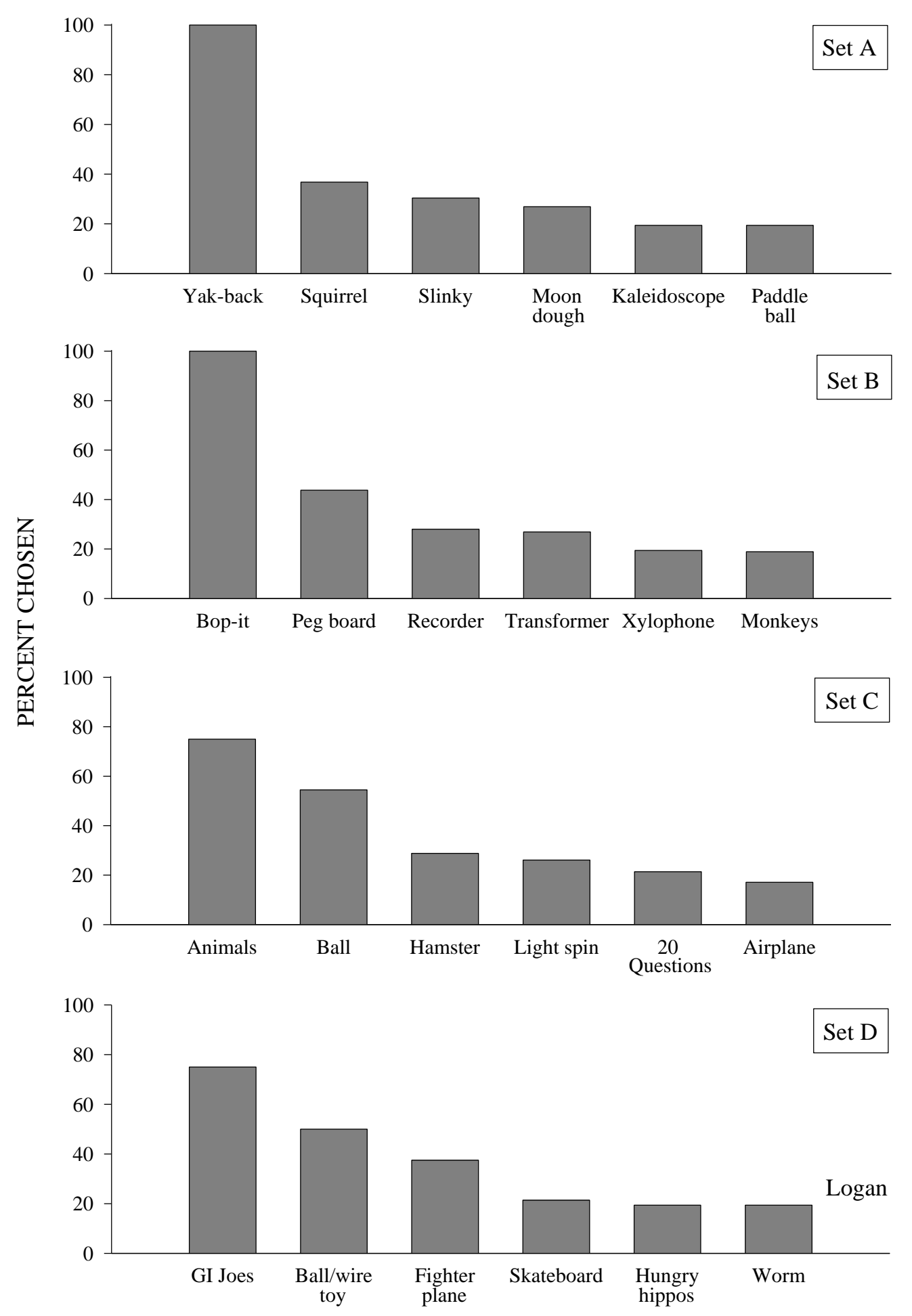

Figure 8: Percentage of opportunities on which a particular toy was selected during MSWO preference assessments across the four sets of toys for Logan. The highest preferred toys (items on the far left of each panel) were each assigned to an integrity level. 

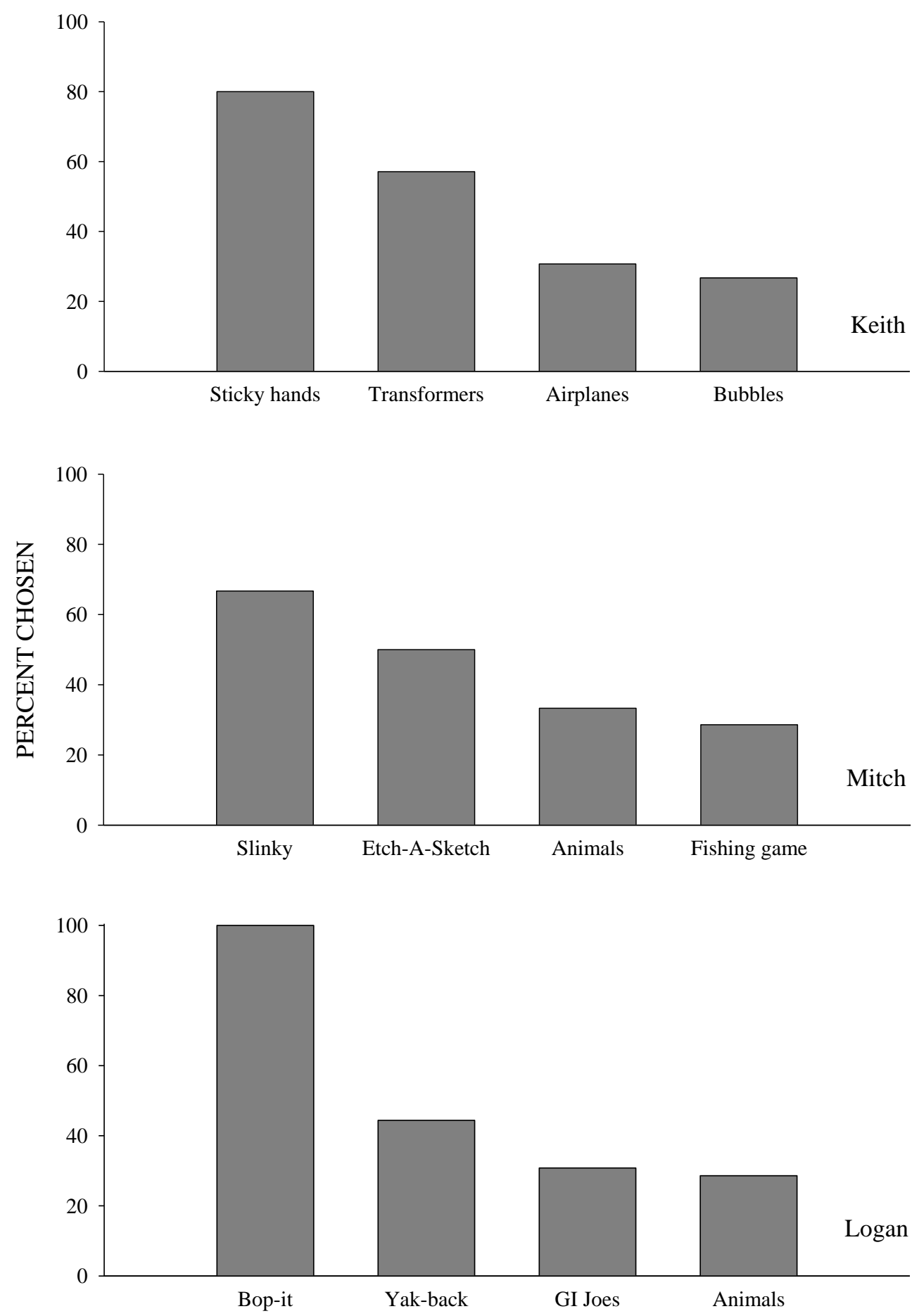

Figure 9: Percentage of opportunities on which a particular toy was selected during MSWO preference assessment with the four highest preferred items from each set of toys for Keith (top panel), Mitch (middle panel), and Logan (bottom panel). 
Figure 10 displays obtained percentage of independent target mands across the four levels of treatment integrity for Keith (top panel), Mitch (middle panel), and Logan (bottom panel). No independent target mands occurred for Keith, Mitch, or Logan during baseline. Independent target mands increased during training for Keith (top panel) in the 40\%, 70\%, and 100\% integrity conditions. Initially, levels of independent target mands were similar across all conditions. Keith met mastery criterion during the $100 \%$ condition first, following 16 training sessions (refer to Table 5). During the remaining sessions, levels of independent target mands occurred at differentially higher levels in the $70 \%$ integrity condition than the $40 \%$ or $0 \%$ conditions. Keith required 30 training sessions to meet mastery criterion in the $70 \%$ integrity condition. Keith maintained low levels of independent target mands during the $40 \%$ integrity condition, and training was discontinued after 31 training sessions. The average percentage of independent target mands across the last six $40 \%$ integrity sessions was $10 \%$. Keith never emitted an independent target mand during the $0 \%$ integrity condition, and training was terminated after 31 training sessions.

During training, Mitch initially engaged in similar levels of independent target mands during the $70 \%$ and $100 \%$ integrity conditions (data shown in Figure 10, middle panel). Mitch met mastery criteria in the $100 \%$ integrity condition after 10 training sessions (refer to Table 5). Mitch required 17 training sessions to meet mastery criteria in the $70 \%$ integrity condition. Mitch engaged in very low levels of independent mands during the $40 \%$ condition (average of $0 \%$ across the last six sessions). Mitch never emitted an independent target mand during the $0 \%$ integrity condition. Training was discontinued in the $0 \%$ and $40 \%$ integrity conditions after 17 training sessions in each condition. 


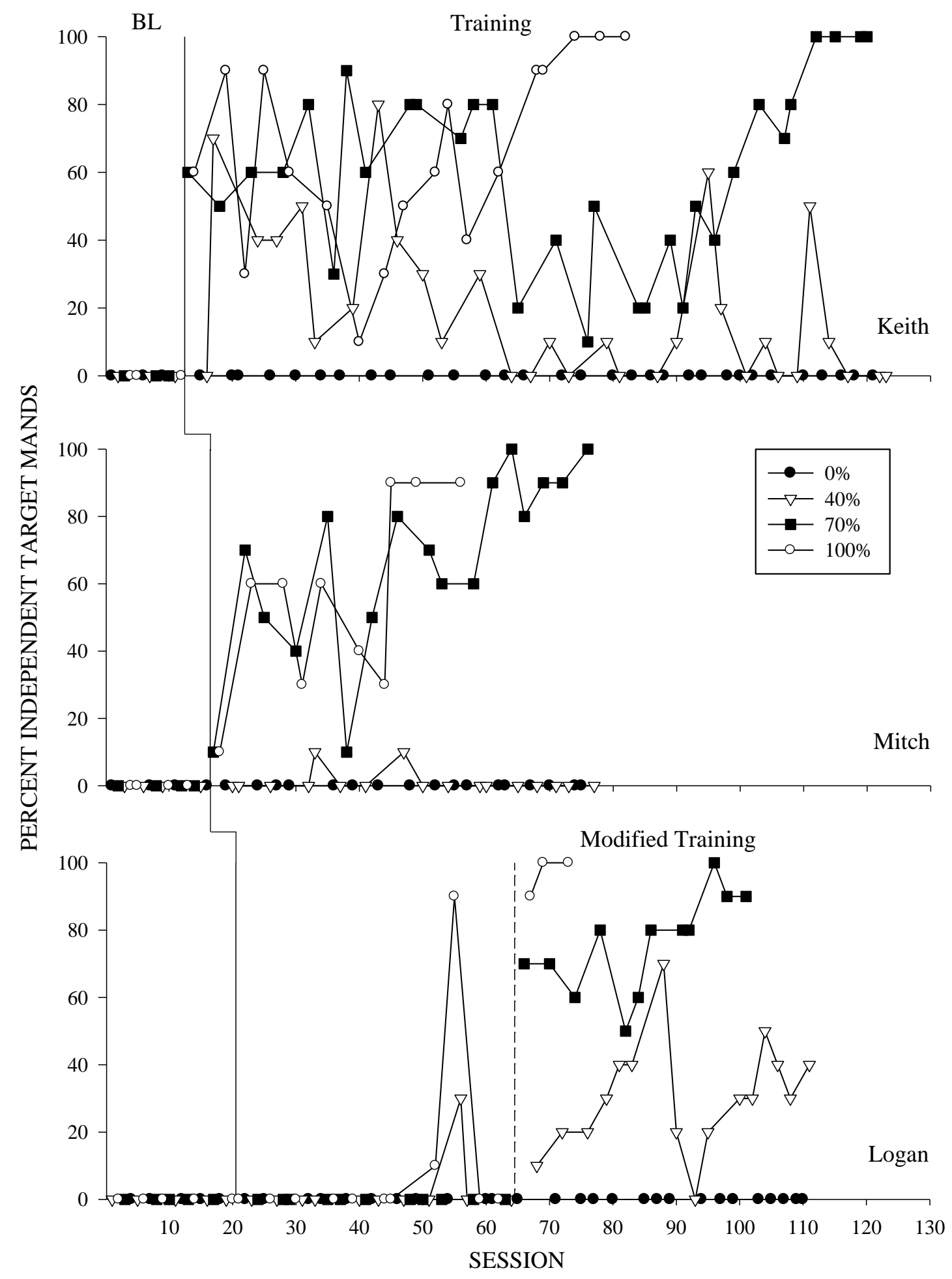

Figure 10: Percentage of correct independent mands with incorrect item delivery during 0\%, 40\%, 70\%, and 100\% integrity sessions across baseline and training for Keith (top panel), Mitch (middle panel), and Logan (bottom panel). 
Table 5

Summary of Independent Target Mands and Session Termination for Experiment 2

\begin{tabular}{ccccccc}
\hline Participant & Condition & $\begin{array}{c}\text { Number of } \\
\text { sessions to } \\
\text { termination }\end{array}$ & $\begin{array}{c}\text { Condition } \\
\text { mastered }\end{array}$ & $\begin{array}{c}\text { Mean correct } \\
\text { last 3 sessions }\end{array}$ & $\begin{array}{c}\text { Mean correct } \\
\text { last 6 sessions }\end{array}$ & $\begin{array}{c}\text { Mean } \\
\text { correct } \\
\text { overall }\end{array}$ \\
\hline Keith & $0 \%$ & 31 & No & $0 \%$ & $0 \%$ & $0 \%$ \\
& $40 \%$ & 31 & No & $0 \%$ & $10 \%$ & $19.4 \%$ \\
& $70 \%$ & 30 & Yes & $100 \%$ & $91.7 \%$ & $60.6 \%$ \\
& $100 \%$ & 16 & Yes & $100 \%$ & $90 \%$ & $66.1 \%$ \\
\hline Mitch & $0 \%$ & 17 & No & $0 \%$ & $0 \%$ & $0 \%$ \\
& 17 & No & $0 \%$ & $0 \%$ & $1.2 \%$ \\
& 17 & Yes & $93.3 \%$ & $91.7 \%$ & $66.5 \%$ \\
& $100 \%$ & 10 & Yes & $90 \%$ & $66.7 \%$ & $56 \%$ \\
& $0 \%$ & 27 & No & $0 \%$ & $0 \%$ & $0 \%$ \\
& $40 \%$ & 27 & No & $36.7 \%$ & $36.7 \%$ & $19.3 \%$ \\
& $70 \%$ & 23 & Yes & $93.3 \%$ & $86.7 \%$ & $39.6 \%$ \\
& $100 \%$ & 14 & Yes & $96.7 \%$ & $63.3 \%$ & $27.9 \%$ \\
\hline
\end{tabular}


Logan engaged in no independent target mands at the onset of training (data shown in Figure 10, bottom panel). During the standard training, Logan independently manded during only three sessions. After 11 training sessions in each integrity condition, modified training was introduced at session 65. Independent target mands increased during modified training in the $40 \%, 70 \%$, and $100 \%$ integrity conditions. Logan met mastery criteria in the $100 \%$ integrity condition after 14 (11 standard and 3 modified) training sessions (refer to Table 5). Following mastery in the $100 \%$ integrity condition, Logan engaged in differentially higher levels of responding in the $70 \%$ integrity condition than the $40 \%$ or $0 \%$ integrity conditions. Logan met mastery criteria in the $70 \%$ integrity condition after 23 training sessions (11 standard and 12 modified). Logan engaged in moderate levels of independent target mands during the $40 \%$ integrity condition with an average of $36.7 \%$ across the last six sessions. Logan never emitted an independent target mand during the $0 \%$ integrity condition. Training was discontinued in the $0 \%$ and $40 \%$ integrity conditions after 27 training sessions in each condition.

\section{Discussion}

Equal opportunities to engage in the target mand were presented across all integrity conditions (the participant had 10 opportunities to engage in the target mand during each session). However, the response requirement differed across conditions and appeared to be a vital component for acquisition. All three participants acquired the target mand with the fewest training sessions in the $100 \%$ integrity condition, suggesting that consistently requiring the response was important to acquisition. Although mastery was acquired with the $70 \%$ integrity condition for all participants, occasional treatment integrity errors were detrimental to acquisition. An additional 7, 9, and 14 training sessions were required for Mitch, Logan, and Keith, respectively, to meet mastery during the $70 \%$ integrity condition compared to the $100 \%$ 
integrity condition. More frequent errors at the $40 \%$ integrity condition were detrimental to acquisition for all participants, with Keith and Logan engaging in some moderate to low levels of independent target mands. Mitch engaged in very low levels of independent manding during the $40 \%$ integrity condition, resulting in levels of responding that were comparable to the $0 \%$ integrity condition. If items were always delivered independent of responding ( $0 \%$ integrity), participants did not acquire the target mand. This suggests that caregivers must arrange the environment, prompt the target mand, and deliver the reinforcer following the response on the majority of opportunities (at least 70\% of opportunities) for acquisition to occur.

One participant (Logan) required modified training procedures for independent target mands to occur. The modified training procedures may be more similar to training procedures used in the natural environment. For example, caregivers may show the target item to the child when prompting a mand. Additionally, caregivers are likely to provide praise when an appropriate mand occurs, especially during training. The presence of the target item and delivery of praise may facilitate mand acquisition in the natural environment where multiple functions of verbal behavior, including mands and tacts (labeling of stimuli in the environment that is reinforced by praise, social interaction, and other conditioned reinforcers) may develop simultaneously. Future research should directly compare different variations of mand-training procedures to identify how to most efficiently teach mands to children.

Delivery of the item contingent on manding is an important component of mand acquisition. Participants required more sessions to acquire the mand even at relatively high levels of integrity (e.g., 70\%), as compared to the $100 \%$ integrity condition. This suggests that caregivers must implement mand-training procedures with near perfect integrity to maximize learning. For example, if a teacher is training a child to mand for "chips," then chips should only 
be delivered following the mand, "chips." If chips are delivered periodically following compliance with academic directives and freely provided at lunch time, the child may acquire the mand "chips" at a slower rate or only engage in the mand "chips" at moderate to low levels.

Independent target mands never occurred when the target response was not required. Therefore, if caregivers do not require a child to ask for items in their environment, it is unlikely that the skills will be acquired. For example, if a teacher always provides a child with a pencil during writing tasks in elementary school, the child may not have the skills necessary to ask for a pencil when given a task and no pencil in middle school.

\section{General Discussion}

The current study extends the literature on treatment integrity errors by examining the effects of errors during mand acquisition. Two types of treatment integrity errors, incorrect item delivery and response-independent item delivery, were parametrically investigated. Consistent with previous literature (e.g., DiGennaro Reed et al., 2011; Noelle et al., 2002), lower levels of treatment integrity were detrimental to skill acquisition for all five participants who acquired mands. Mand training implemented with $100 \%$ integrity resulted in faster acquisition of manding compared to mand training implemented with reduced integrity $(70 \%, 40 \%$ and $0 \%$ integrity).

Different types of treatment integrity errors may have differential effects on acquisition. In some situations, lower levels of treatment integrity may still result in acquisition. Two of three participants in Experiment 1 mastered at least one mand when treatment integrity was reduced (0\% integrity for Miles and $40 \%$ and $70 \%$ integrity for Paige). However, acquisition was not observed across all integrity levels for both participants. Similarly, Worsdell and colleagues (2005) compared the number of sight words mastered when an error-correction 
procedure was implemented at $100 \%$ integrity or $33 \%$ integrity. Although more words were acquired in the $100 \%$ integrity condition, mastery of sight words occurred during the $33 \%$ integrity condition. Findings from Experiment 1 suggest that although incorrect-item delivery may slow acquisition, children may acquire some mands when unmatched items are intermittently delivered.

For other types of errors, acquisition may not occur at low levels of treatment integrity. None of the participants in Experiment 2 acquired the target mand at $40 \%$ and $0 \%$ integrity. Previous research has obtained high levels of performance at 100\% integrity, but low levels of performance at 50\% or less integrity (DiGennaro Reed et al., 2011; Noelle et al., 2002; Wilder et al., 2006). Reduced levels of performance when integrity is at or below $50 \%$ has been observed across a range of errors, including delivering the reinforcer before an error-correction procedure following incorrect responses (DiGennaro Reed et al.) and omitting three-step prompting for noncompliance (Wilder et al.). Findings from Experiment 2 suggest that response-independent item delivery has similar detrimental effects as these other types of errors.

To date, the variables that influence what errors can occur at moderate levels and still result in mastery of skills, albeit at a slower rate (Experiment 1), and what errors will prevent mastery of skills (Experiment 2) are unknown. Much of the previous research on treatment integrity during response acquisition has focused on incorrect responding (e.g., prompting noncompliance, implementing error-correction procedures, and delivering reinforcers following incorrect responses). The literature is mixed on the level of integrity necessary for eventual acquisition to occur. For example, it is unclear why sight words were acquired at $33 \%$ integrity in one study (error-correction procedures were omitted; Worsdell et al., 2005), but shape identification was not acquired at 50\% integrity in another study (praise and tokens were 
delivered after incorrect responses; DiGennaro Reed et al., 2011). A key component for acquisition may be the correct delivery of the reinforcer. Delivery of the reinforcer independent of responding (Experiment 2) or following an incorrect response (DiGennaro Reed et al.) was detrimental to acquisition. During both of these investigations, integrity at or below 50\% prevented mastery of skills.

During both Experiment 1 and Experiment 2, least-to-most prompting was effective to teach at least two target mands for five of six participants. The number of trials required to meet mastery criteria varied across participants. Paige and Mitch each required 100 trials for mastery of their first mand. Logan mastered his first mand after 140 trials, Keith after 160 trials, and Miles required 330 trials. Isaac did not acquire the target mand following 350 training trials during the $100 \%$ integrity condition. During Experiment 1, Miles and Paige were required to emit a response on every trial to receive the toy. Miles required 380 trials to meet mastery on a second mand (0\% integrity) and failed to acquire the other two targeted mands (40\% and 70\% integrity) after 450 training trials. Paige required 190 trials to meet mastery on a second mand (40\% integrity), 240 trials to meet mastery on a third mand (70\% integrity), and failed to acquire the final mand ( $0 \%$ integrity) after 240 training trials.

Similar numbers of trials have been reported in previous mand-training literature. However, these studies focused on children who engaged in limited verbal behavior. For example, Bourret and colleagues (2004) taught children who communicated using gestures to vocally mand for a toy. Acquisition occurred at 120 trials for one participant. For the other participant, 350 trials were conducted, but consistent independent manding above $80 \%$ was not observed. Simic and Bucher (1980) did not report individual training data for each of their five participants. However, the authors did report that training trials varied from 32 to 686 with an 
average of 275 trials required for acquisition. Yamamoto and Mochizuki (1988) trained three children who requested objects using one- or two-word sentences following adult prompting. A total of 48, 66, and 198 trials were required for mand acquisition for the three participants, respectively.

The participants in the current study had delayed mand repertoires, but communicated using full sentences and used vocal mands to request for items, activities, and information in their classrooms. Previous studies suggest that training children with these repertoires should require relatively few trials. For example, Shillingsburg and colleagues (2011) trained two participants diagnosed with autism to ask Wh-questions (who, which, and when). One participant required 25, 30, and 20 training trials for who, which, and when, respectively. The other participant required 20, 30, and 50 training trials. Petursdottir and colleagues (2005) trained four typically developing children between 2 to 3 years old. Participants required an average of $20,39,78$, and 84 trials to meet mastery for each mand trained.

The number of training trials required for acquisition of target mands given the repertories of the participants in the current study was surprising. The minimum number of training trials in the current study was 100 with up to 380 trials required for acquisition. The arrangement of the training session in the current study may have impeded acquisition. Shillingsburg and colleagues (2011) and Petursdottir and colleagues (2005) provided instructions as part of their training procedures, which may have speeded acquisition of the target mand. These instructions may have been more salient to the participants than the orienting response (looking at the item) and the removal of an item used in the current study.

The number of trials required to meet mastery criteria was not differentially affected by the participant's diagnosis or functioning level. For example, having a diagnosis of a 
developmental disability was not related to performance. Isaac had a diagnosis of autism and did not acquire any mands. However, Mitch and Paige were diagnosed with PDD-NOS and Down Syndrome, respectively, and required the fewest training of all participants to meet mastery criterion. Similarly, functioning level was not predictive of performance. Logan was the highest functioning participant. He had the most academic skills and most sophisticated verbal repertoire of all participants. However, Logan required modified training procedures and more training trials to master mands than lower-functioning participants (Paige and Mitch) with substantially fewer academic and verbal skills. Miles was also a higher functioning individual than Paige, Mitch, and Keith, but Miles required the most training trials (330) of all participants to meet mastery.

It seems more important to consider the similarity of behavioral repertoires than specific diagnoses of individuals when evaluating skills-training procedures. In the current study, mand training was implemented with six individuals who had similar behavioral repertoires, including communicating vocally using full sentences, emitting some independent mands in their classrooms, following one-step directives, imitating two-syllable nonsense words, and engaging with toys. Standard mand training effectively trained mands for four individuals across a range of diagnoses and modified mand training was required to teach mands to a fifth individual. However, neither the standard or modified training resulted in acquisition for the sixth participant. Future research could more thoroughly explore if certain behavioral repertoires or diagnoses predict positive outcomes during mand training.

Restriction of items in the current study may not have created establishing operations for the target mand and impeded acquisition for some participants. Petursdottir and colleagues (2005) arranged establishing operations by removing a piece of a puzzle or cube that participants 
were asked to complete. This arrangement may be more effective in creating establishing operations and may explain some of the differences in the number of trials required for mastery. However, similar to the current study, Shillingsburg and colleagues (2011) arranged establishing operations by restricting access to a highly preferred item. In the current study, participants were required to emit the target mand and the item was delivered. Shillingsburg and colleagues required participants to emit the target mand and then information was provided about the restricted item. Participants had to use the information to obtain the preferred item (e.g., go to the correct person to retrieve the item). It is unclear how these differences in training arrangements between Shillingsburg and colleagues and the current study would have led to differences in establishing operations or explain the differences in training trials required for mastery.

Another interesting finding was the lack of acquisition for some participants during Experiment 1. For example, 450 training trials were conducted with Miles during each of two conditions. Similarly, 350 training trials were conducted with Isaac during one condition. Despite this number of training trials, Miles and Isaac did not acquire the target mand associated with these conditions. Little research has directly examined the components of mand training that help facilitate mand acquisition. Although some acquisition was observed for Miles, little acquisition was observed with Isaac. It is possible that they may have acquired the target mands if different prompting procedures were used. In the current study, least-to-most prompting was used. An alternative prompting procedure is most-to-least prompting. During most-to-least prompting, the target mand is modeled immediately following the restriction of the item. The prompts are faded over time until the child responds correctly and independently. This could reduce the likelihood and frequency of incorrect responses (e.g., Libby et al., 2008). Reducing 
the likelihood of incorrect responses may contribute to faster rates of mand acquisition. Future research could compare least-to-most and most-to-least prompt hierarchies on rates of mand acquisition and evaluate the likelihood of errors occurring during each of these prompting procedures.

For two of the participants in the current study, the standard training did not result in acquisition of any target mands. For these two participants (Logan and Isaac), a modified training procedure was implemented. The modified training was effective to teach mands to Logan, but not Isaac. The modified training procedures may mimic teaching arrangements in the natural environment. Caregivers often use naturally occurring opportunities to have children mand. Frequently, such opportunities include the presentation of the target item. Presenting the target item with prompting has been used to train mands in research studies as well (e.g., Jennett et al., 2008; Kodak \& Clements, 2009). The presentation of the target item and then systematically fading of the item may contribute to acquisition. Future research could compare prompting procedures that do and do not involve the presentation of the target item on rates of mand acquisition.

In the current study, data were not collected on problem behavior or item engagement during the session. Isaac engaged in some problem behavior during sessions that may have impeded acquisition. It may be helpful for future research to evaluate the prevalence of problem behavior during sessions and if problem behavior occurs differentially across integrity levels. Additionally, anecdotal observations of two participants in Experiment 2 (Mitch and Logan) suggested that item engagement decreased over sessions during low integrity conditions (40\% and $0 \%$ integrity). Future research should investigate the influence of response-independent item delivery on item engagement. 
The current study evaluated the effects of two types of treatment integrity errors on mand acquisition. In addition to the errors evaluated in the current study, several other types of errors can occur during the three general components of mand training: establishing operations, target response, and reinforcement. Errors can be made when attempting to arrange an establishing operation. For example, a caregiver observes a child reaching for an object, such as a cookie. The caregiver hands the child the cookie. When the child already has access to the cookie, the caregiver prompts the child to emit the response, "cookie." In this situation, the prompt for the mand occurs once the child already has access to the item and thus, in the absence of the establishing operation. Future research could evaluate how manipulating the establishing operation by providing the participant with access to the item before prompting the target mand influences mand acquisition.

Errors can be made during mand training when prompting the target response. For example, therapists may omit steps in the prompting hierarchy (e.g., fail to deliver a partial prompt) or deliver inaccurate vocal prompts (e.g., prompt the child to say the incorrect word or state part of the word incorrectly in the prompt). The effects of errors may depend on the programed delay between prompts and whether least-to-most or most-to-least prompting is used. The effects of errors during prompting on mand acquisition are currently unknown.

Errors can be made when the reinforcing stimulus is delivered following the target response. For example, caregivers may deliver the correct item, but there may be a delay between the mand and the item delivery. Future research could evaluate whether this delay to item delivery is detrimental to mand acquisition. The current study evaluated the effects of incorrect item delivery when the incorrect item was another toy. It is possible that the delivery of incorrect items that are less preferred (e.g., the child asks for a "cookie" and is given broccoli) 
or are unrelated to the situation (e.g., the child asks for a missing puzzle piece and is given a sock) have different effects on acquisition.

In summary, mand training should be implemented with high levels of integrity for mastery of target mands to occur. Specifically, delivering the item independent of responding and delivering an item unmatched to the target mand impeded acquisition. Structured mand training is an important component of early intervention, especially for children with developmental disabilities. The current study investigated the effects of treatment integrity errors with participants who already had some independent mands in their repertoire. It is likely that these errors will be detrimental to mand acquisition for children who have few, if any, mands in their repertoires. When training caregivers to conduct mand training, training should focus on ensuring that caregivers are able to implement mand-training procedures fluently and in the absence of errors.

The current study examined the effects of treatment integrity errors on mand acquisition. It is unknown how treatment integrity errors influence the maintenance of the mand or the generalization of the mand. It is possible that although lower levels of treatment integrity slowed mand acquisition, it may have little effect on maintenance of the mand. In some cases, generalization of a mand is appropriate and is a beneficial side-effect of training. For example, if a child was trained to ask for a car, a goal of training would be for the child to use the mand, "car" to ask for the training stimulus as well as other cars in his environment. In other cases, a mand can overgeneralize and be used inappropriately. For example, if a child was trained to ask for a car, a goal of training would be for the child to mand, "car" only for a car and not to use the mand, "car" to ask for a train. The extent to which the mands acquired during the current study would generalize to other appropriate and inappropriate stimuli are unknown. Future research 
should investigate the effects of errors during mand training on maintenance and generalization of target mands. 


\section{References}

Bancroft, S. L., Weiss, J. S., Libby, M. E., \& Ahearn, W. H. (2011). A comparison of procedural variations in teaching behavior chains: Manual guidance, trainer completion, and no completion of untrained steps. Journal of Applied Behavior Analysis, 44, 559569. doi:10.1901/jaba.2011.44-559

Bourret, J., Vollmer, T. R., \& Rapp, J. T. (2004). Evaluation of a vocal mand assessment and vocal mand training procedures. Journal of Applied Behavior Analysis, 37, 129-144. doi:10.1901/jaba.2004.37-129

Bowman, L. G., Fisher, W. W., Thompson, R. H., \& Piazza, C. C. (1997). On the relation of mands and the function of destructive behavior. Journal of Applied Behavior Analysis, 30, 251-265. doi:10.1901/jaba.1997.30-251

Brown, K. A., Wacker, D. P., Derby, K. M., Peck, S. M., Richman, D. M., Sasso, G. M.,... Harding, J. W. (2000). Evaluating the effects of functional communication training in the presence and absence of establishing operations. Journal of Applied Behavior Analysis, 33, 53-71. doi:10.1901/jaba.2000.33-53

Carr., E. G., \& Durand, V. M. (1985). Reducing behavior problems through functional communication training. Journal of Applied Behavior Analysis, 18, 111-126. doi:10.1901/jaba.1985.18-111

Carr, E. G., \& Kologinsky, E. (1983). Acquisition of sign language by autistic children II: Spontaneity and generalization effects. Journal of Applied Behavior Analysis, 16, 297314. doi:10.1901/jaba.1983.16-297

Day, R. M., Rea, J. A., Schussler, N. G., Larsen, S. E., \& Johnson, W. L. (1988). A functionally 
based approach to the treatment of self-injurious behavior. Behavior Modification, 12, 565-589.

DeLeon, I. G., \& Iwata, B. A. (1996). Evaluation of a multiple-stimulus presentation format for assessing reinforcer preferences. Journal of Applied Behavior Analysis, 29, 519-533. doi:10.1901/jaba.1996.29-519

DiGennaro, F. D., Martens, B. K., \& Kleinmann, A. E. (2007). A comparison of performance feedback procedures on teachers' treatment implementation integrity and students' inappropriate behavior in special education classrooms. Journal of Applied Behavior Analysis, 40, 611-615. doi:10.1901/jaba.2007.40-447

DiGennaro Reed, F. D., Reed, D. D., Catania, C. N., \& Maquire, H. (2011). A parametric analysis of errors of commission during discrete-trial training. Journal of Applied Behavior Analysis, 44, 611-615. doi:10.1901/jaba.2011.44-611

Gates, G. L., \& Dalenberg, A. E. (2005). Effects of interspersing rate on student preferences for mathematics assignments. Journal of Behavioral Education, 14, 89-103. doi:10.1007/s19864-005-2704-y

Gregory, M. K., DeLeon, I. G., \& Richman, D. M. (2009). The influence of matching and motor-imitation abilities on rapid acquisition of manual signs and exchange-based communicative responses. Journal of Applied Behavior Analysis, 42, 399-404. doi:10.1901/jaba.2009.42-399

Grow, L. L., Carr, J. E., Gunby, K. V., Charania, S. M., Gonsalves, L., Ktaech, I. A., \& Kisamore, A. N. (2009). Deviations from prescribed prompting procedures: Implications for treatment integrity. Journal of Behavioral Education, 18, 142-156. doi:10.1007/s10864-009-9085-6 
Grow, L. L., Carr, J. E., Kodak, T. M., Jostad, C. M., \& Kisamore, A. N. (2011). A comparison of methods for teaching receptive labeling to children with autism spectrum disorders. Journal of Applied Behavior Analysis, 44, 475-498. doi:10.1901/jaba.2011.44-475

Ingvarsson, E. T., \& Hollobaugh, T. (2010). Acquisition of intraverbal behavior: Teaching children with autism to mand for answers to questions. Journal of Applied Behavior Analysis, 43, 1-17. doi:10.1901/jaba.2010.43-1

Iwata, B. A., Dorsey, M. F., Slifer, K. J., Bauman, K. E., \& Richman, G. S. (1994). Toward a functional analysis of self-injury. Journal of Applied Behavior Analysis, 27, 197-209. doi:10.1901/jaba.1994.27-197. (Reprinted from Analysis and Intervention in Developmental Disabilities, 2, 3-20, 1982).

Jennett, H. K., Harris, S. L., \& Delmolino, L. (2008). Discrete trial instruction vs. mand training for teaching children with autism to make requests. The Analysis of Verbal Behavior, 24, 69-85.

Kahng, S., Iwata, B. A., Thompson, R. H., \& Hanley, G. P. (2000). A method for identifying satiation versus extinction effects under noncontingent reinforcement schedules. Journal of Applied Behavior Analysis, 33, 419-432. doi:10.1901/jaba.2000.33-419

Kodak, T., \& Clements, A. (2009). Acquisition of mands and tacts with concurrent echoic training. Journal of Applied Behavior Analysis, 42, 839-843. doi:10.1901/jaba.2009.42839

Koegel, L. K., Koegel, R. L., Green-Hopkins, I., \& Barnes, C. C. (2010). Brief report: Question-asking and collateral language acquisition in children with autism. Journal of Autism and Developmental Disorders, 40, 509-515. doi:10.1007/s10803-009-0896-z

Lattal, K. A. (1974). Combinations of response-reinforcer dependence and independence. 
Journal of the Experimental Analysis of Behavior, 22, 357-362.

doi:10.1901/jeab/1974.22-357

Lattal, K. A., \& Maxey, G. C. (1971). Some effects of response independent reinforcers in multiple schedules. Journal of the Experimental Analysis of Behavior, 26, 225-231. doi:10.1901/jeab/1971.16-225

Libby, M. E., Weiss, J. S., Bancroft, S., \& Ahearn, W. H. (2008). A comparison of most-toleast and least-to-mots prompting on the acquisition of solitary play skills. Behavior Analysis in Practice, 1, 37-43.

Lieving, G. A., Reilly, M. P., \& Lattal, K. A. (2006). Disruption of responding maintained by conditioned reinforcement: Alternations in response-conditioned-reinforcer relations. Journal of the Experimental Analysis of Behavior, 86, 197-209. doi:10.1901/jeab/2006.12-05

Luczynski, K. C., \& Hanley, G. P. (2010). Examining the generality of children's preference for contingent reinforcement via extension to different responses, reinforcers, and schedules. Journal of Applied Behavior Analysis, 43, 397-409. doi:10.1901/jaba.2010.43-397

Michael, J. (1982). Distinguishing between discriminative and motivational functions of stimuli. Journal of the Experimental Analysis of Behavior, 37, 149-155. doi:10.1901/jeab.1982.37-149

Neef, N. A., Iwata, B. A., \& Page, T. J. (1980). The effects of interspersal training versus highdensity reinforcement on spelling acquisition and retention. Journal of Applied Behavior Analysis, 13, 153-158. doi:10.1901/jaba.1980.13-153

Noelle, G. H., Gresham, F. M., \& Gansle, K. A. (2002). Does treatment integrity matter? A 
preliminary investigation of instructional implementation and mathematics performance. Journal of Behavioral Education, 11, 51-67. doi:10.1023/A:1014385321849

Petursdottir, A. I., Carr, J. E., \& Michael, J. (2005). Emergence of mands and tacts of novel objects among preschool children. The Analysis of Verbal Behavior, 21, 59-74.

Rhymer, K. N., \& Morgan, S. K. (2005). Comparison of the explicit timing and interspersal interventions: Analysis of problem completion rates, student preference, and teacher acceptability. Journal of Behavioral Education, 14, 283-303. doi:10.1007/s10864-005$8651-9$

Simic, J., \& Bucher, B. (1980). Development of spontaneous manding in language deficient children. Journal of Applied Behavior Analysis, 13, 523-528. doi:10.1901/jaba.1980.13523

Shillingsburg, M. A., Valentino, A. L., Bowen, C. N., Bradley, D., \& Zavatkay, D. (2011). Teaching children with autism to request information. Research in Autism Spectrum Disorders, 5, 670-679. doi:10.1016/j.rasd.2010.08.004

Skinner, B. F. (1957). Verbal behavior. Cambridge, MA: Prentice-Hall, Inc.

St. Peter Pipkin, C., Vollmer, T. R., \& Sloman, K. N. (2010). Effects of treatment integrity failures during differential reinforcement of alternative behavior: A translational model. Journal of Applied Behavior Analysis, 43, 47-70. doi:10.1901/jaba.2010.43-47

Tiger, J. H., \& Hanley, G. P. (2004). Developing stimulus control of preschooler mands: An analysis of schedule-correlated and contingency-specifying stimuli. Journal of Applied Behavior Analysis, 37, 517-521. doi:10.1901/jaba.2004.37-517

Tincani, M. (2004). Comparing the picture exchange communication system and sign language 
training for children with autism. Focus on Autism and Other Developmental Disabilities, 19, 152-163.

Vollmer, T. R., Iwata, B. A., Zarcone, J. R., Smith, R. G., \& Mazaleski, J. L. (1993). The role of attention in the treatment of attention-maintained self-injurious behavior: Noncontingent reinforcement and differential reinforcement of other behavior. Journal of Applied Behavior Analysis, 26, 9-21. doi:10.1901/jaba.1993.26-9

Vollmer, T. R., Roane, H. S., Ringdahl, J. E., \& Marcus, B. A. (1999). Evaluating treatment challenges with differential reinforcement of alternative behavior. Journal of Applied Behavior Analysis, 32, 9-23. doi:10.1901/jaba.1999.32-9

Wilder, D. A., Atwell, J., \& Wine, B. (2006). The effects of varying levels of treatment integrity on child compliance during treatment with a three-step prompting procedure. Journal of Applied Behavior Analysis, 39, 369-373. doi:10.1901/jaba.2006.144-05

Winborn, L., Wacker, D. P., Richman, D. M., Asmus, J., \& Geier, D. (2002). Assessment of mand selection for functional communication training packages. Journal of Applied Behavior Analysis, 35, 295-298. doi:10.1901/jaba.2002.35-295

Winborn-Kemmerer, L., Ringdahl, J. E., Wacker, D. P., \& Kitsukawa, K. (2009). A demonstration of individual preference for novel mands during functional communication training. Journal of Applied Behavior Analysis, 42, 185-189. doi:10.1901/jaba.2009.42185

Worsdell, A. S., Iwata, B. A., Dozier, C. L., Johnson, A. D., Neidert, P. L., \& Thompson, J. L. (2005). Analysis of response repetition as an error-correction strategy during sight-word reading. Journal of Applied Behavior Analysis, 38, 511-527. doi:10.1901/jaba.2005.11504 
Yamamoto, J., \& Mochizuki, A. (1988). Acquisition and functional analysis of manding with autistic students. Journal of Applied Behavior Analysis, 21, 57-64.

doi:10.1901/jaba.1988.21-57 


\section{Appendix A}

Protocol: Probe for Echoic Skills

1. The therapist will conduct a MSWO preference assessment with edible items. The two highest preferred edible items identified through the MSWO assessment will be delivered for correct responses during the probe sessions.

2. The therapist will sit down at a table across from the student. The therapist will state, "We are going to practice saying some funny-sounding words. You say the word exactly as I say it and you can earn [edible names].”

3. The therapist will present 10 trials by selecting words from the below list. At the beginning of each trial, the therapist state "Say, X" where X is the target word.

4. Following correct responses, the therapist will deliver a small edible.

5. Following incorrect responses, the therapist will refrain from commenting, wait $10 \mathrm{~s}$, and then move on to the next trial.

$\begin{array}{lll}\text { Piff/een } & \text { Thray/ooks } & \text { Nass/tooce } \\ \text { Biss/zeet } & \text { Smee/oast } & \text { Thazz/hoon } \\ \text { Siff/feep } & \text { Slee/ips } & \text { Bipe/zoin } \\ \text { Zip/reen } & \text { Gree/ooth } & \text { Fide/voin } \\ \text { Chid/leet } & \text { Yazz/noop } & \text { Nize/thoin } \\ \text { Mib/meeg } & \text { Pag/boop } & \text { Zipe/thoig } \\ \text { Proy/eeps } & \text { Mab/moof } & \text { Rine/doin } \\ \text { Froo/anth } & \text { Dat/poom } & \text { Dite/choid }\end{array}$




\section{Appendix B}

Data Collection Sheet for Experiment 1, Incorrect Item Delivery:

Data Collect Codes:

$(+)=$ Independent, correct response

$(+\mathrm{NS})=$ Correct following nonspecific prompt

$(+\mathrm{PV})=$ Correct following partial vocal prompt

$(+\mathrm{FV})=$ Correct following full vocal prompt
$(-)=$ Independent, incorrect response

(-NS) = Incorrect following nonspecific prompt

$(-\mathrm{PV})=$ Incorrect following partial prompt

$(-\mathrm{FV})=$ Incorrect following full prompt

$(\mathrm{NR})=$ No response

Date:

Therapist:

Script \#

Session \#:

Data Collector:

Condition:

Primary/Reli (circle one)

\begin{tabular}{|c|c|l|l|l|l|}
\hline Trial & $\begin{array}{c}\text { Full } \\
\text { or } \\
\text { Error } \\
\text { Trial }\end{array}$ & Initial Vocal Response & $\begin{array}{c}\text { Data on } \\
\text { Initial } \\
\text { Response }\end{array}$ & $\begin{array}{c}\text { Data on } \\
\text { Target } \\
\text { Response } \\
\text { (only take if not } \\
\text { initial response) }\end{array}$ & Item Delivered \\
\hline 1 & & & & & \\
\hline 2 & & & & & \\
\hline 3 & & & & & \\
\hline 4 & & & & & \\
\hline 5 & & & & & \\
\hline 6 & & & & & \\
\hline 7 & & & & & \\
\hline 8 & & & & & \\
\hline 9 & & & & & \\
\hline 10 & & & & & \\
\hline
\end{tabular}




\section{Appendix C}

Examples of Predetermined sequences:

0\% Integrity:

\begin{tabular}{|c|c|}
\hline Trial & Full or Error \\
\hline 1 & Error \\
\hline 2 & Error \\
\hline 3 & Error \\
\hline 4 & Error \\
\hline 5 & Error \\
\hline 6 & Error \\
\hline 7 & Error \\
\hline 8 & Error \\
\hline 9 & Error \\
\hline 10 & Error \\
\hline
\end{tabular}

40\% Integrity:

\begin{tabular}{|c|c|}
\hline Trial & Full or Error \\
\hline 1 & Full \\
\hline 2 & Error \\
\hline 3 & Error \\
\hline 4 & Error \\
\hline 5 & Error \\
\hline 6 & Error \\
\hline 7 & Full \\
\hline 8 & Full \\
\hline 9 & Error \\
\hline 10 & Full \\
\hline
\end{tabular}

70\% Integrity:

\begin{tabular}{|c|c|}
\hline Trial & Full or Error \\
\hline 1 & Full \\
\hline 2 & Full \\
\hline 3 & Error \\
\hline 4 & Error \\
\hline 5 & Full \\
\hline 6 & Full \\
\hline 7 & Error \\
\hline 8 & Full \\
\hline 9 & Full \\
\hline 10 & Full \\
\hline
\end{tabular}

100\% Integrity:

\begin{tabular}{|c|c|}
\hline Trial & Full or Error \\
\hline 1 & Full \\
\hline 2 & Full \\
\hline 3 & Full \\
\hline 4 & Full \\
\hline 5 & Full \\
\hline 6 & Full \\
\hline 7 & Full \\
\hline 8 & Full \\
\hline 9 & Full \\
\hline 10 & Full \\
\hline
\end{tabular}

\begin{tabular}{|c|c|}
\hline Trial & Full or Error \\
\hline 1 & Error \\
\hline 2 & Error \\
\hline 3 & Error \\
\hline 4 & Full \\
\hline 5 & Full \\
\hline 6 & Error \\
\hline 7 & Error \\
\hline 8 & Error \\
\hline 9 & Full \\
\hline 10 & Full \\
\hline
\end{tabular}

\begin{tabular}{|c|c|}
\hline Trial & Full or Error \\
\hline 1 & Error \\
\hline 2 & Full \\
\hline 3 & Error \\
\hline 4 & Full \\
\hline 5 & Error \\
\hline 6 & Full \\
\hline 7 & Error \\
\hline 8 & Error \\
\hline 9 & Error \\
\hline 10 & Full \\
\hline
\end{tabular}

\begin{tabular}{|c|c|}
\hline Trial & Full or Error \\
\hline 1 & Full \\
\hline 2 & Full \\
\hline 3 & Full \\
\hline 4 & Full \\
\hline 5 & Full \\
\hline 6 & Error \\
\hline 7 & Full \\
\hline 8 & Full \\
\hline 9 & Error \\
\hline 10 & Error \\
\hline
\end{tabular}

\begin{tabular}{|c|c|}
\hline Trial & Full or Error \\
\hline 1 & Error \\
\hline 2 & Full \\
\hline 3 & Full \\
\hline 4 & Full \\
\hline 5 & Full \\
\hline 6 & Full \\
\hline 7 & Error \\
\hline 8 & Full \\
\hline 9 & Error \\
\hline 10 & Full \\
\hline
\end{tabular}




\section{Appendix D}

Data Collection Sheet for Experiment 2, Response-Independent Item Delivery:

Data Collect Codes:
$(+)=$ Independent, correct response
$(-)=$ Independent, incorrect response
$(+\mathrm{NS})=$ Correct following nonspecific
$(-\mathrm{NS})=$ Incorrect following nonspecific prompt
prompt
$(+\mathrm{PV})=$ Correct following partial prompt
$(-\mathrm{PV})=$ Incorrect following partial prompt
$(+\mathrm{FV})=$ Correct following vocal prompt
$(-\mathrm{FV})=$ Incorrect following full prompt
$(\mathrm{NR})=$ No response

Date:

Session \#:

Condition:
Therapist:

Data Collector:

Primary/Reli (circle one)

\begin{tabular}{|c|c|l|l|l|l|}
\hline Trial & $\begin{array}{c}\text { Full } \\
\text { or } \\
\text { Error } \\
\text { Trial }\end{array}$ & Initial Vocal Response & $\begin{array}{c}\text { Data on } \\
\text { Initial } \\
\text { Response }\end{array}$ & $\begin{array}{c}\text { Check if Initial } \\
\text { Response Came } \\
\text { After Toy } \\
\text { (only take if not initial response) } \\
\text { Delivery on Error } \\
\text { Trials. }\end{array}$ \\
\hline 1 & & & & & \\
\hline 2 & & & & & \\
\hline 3 & & & & & \\
\hline 4 & & & & & \\
\hline 5 & & & & & \\
\hline 6 & & & & & \\
\hline 7 & & & & & \\
\hline 8 & & & & & \\
\hline 9 & & & & & \\
\hline 10 & & & & & \\
\hline
\end{tabular}

